\title{
A Rising E-Channel Tide Lifts All Boats? The Impact of Manufacturer Multichannel Encroachment on Traditional Selling and Leasing
}

\author{
Wei Yan, ${ }^{1}$ Youwei $\mathrm{Li}^{2}{ }^{2}$ Ying $\mathrm{Wu}^{3}$ and Mark Palmer ${ }^{2}$ \\ ${ }^{1}$ School of Management and Economics, University of Electronic Science and Technology of China, Chengdu 611731, China \\ ${ }^{2}$ School of Management, Queen's University Belfast, Belfast BT9 5EE, UK \\ ${ }^{3}$ The Management School, Chongqing University of Science and Technology, Chongqing 401331, China \\ Correspondence should be addressed to Youwei Li; y.li@qub.ac.uk
}

Received 7 November 2015; Revised 31 March 2016; Accepted 17 April 2016

Academic Editor: Paolo Renna

Copyright (C) 2016 Wei Yan et al. This is an open access article distributed under the Creative Commons Attribution License, which permits unrestricted use, distribution, and reproduction in any medium, provided the original work is properly cited.

\begin{abstract}
Organizing and managing channels of distribution is an important marketing task. Due to the emergence of electronic commerce on the Internet, e-channel distribution systems have been adopted by many manufacturers. However, academic and anecdotal evidence both point to the pressures arising from this new e-channel manufacturing environment. Question marks therefore remain on how the addition of this e-channel affects the traditional marketing strategies of leasing and selling. We set up several twoperiod dual-channel models in which a manufacturer sells a durable product through both a manufacturer-owned e-channel and an independent reseller (leaser) who adopts selling (leasing) to consumers. Our main results indicate that, direct selling cost aside, product durability plays an important role in shaping the strategies of all members. With either marketing strategy, the additional expansion of an e-channel territory may secure Pareto gains, in which all members benefit.
\end{abstract}

\section{Introduction}

Exclusive channel territories are one of the oldest fields of marketing distribution scholarly activity (e.g., $[1,2])$. For years, organizing and managing distribution channels has been an integral part of contractual work of the manufacturer's marketing strategy [3-5]. Exclusive territories would normally form part of the vertical restraint of members of the distribution channel, by which one member undertakes not to market his products in a geographical area $[1,4,6$, 7]. However, traditional distribution channels and related strategies have been impacted by the emergence, disruption, and transformational effects of the Internet and the creation of virtual marketplace opportunities. With the realignment of, or new investment in, associated technologies, the capacity of manufacturers to search for business and active sales outside that same market through e-channels has become an important way to minimize their costs, reach different customer segments, and remain competitive [8]. As a consequence, many manufacturing firms, including Apple [9], HP [10], and Lenovo [11], have begun to distribute their products and reach their customers simultaneously through new echannels, which are both integrated and independent (e.g., [4]). As such, e-channels have reset many of the exclusive clause contracts and relational business norms associated with traditional distribution channel strategies. With the Internet and e-channels, channel management is no longer bound or restricted to the traditional market geographies and distribution channels for leasing and selling.

The addition of manufacturer-owned e-channels to traditional channels of selling and leasing channel practice has, however, not been without its pressures, tensions, and conflict [12]. Academic and anecdotal evidence both point to the stresses arising from new e-channel environment where new and direct manufacturing channels have challenged exclusive channel territories, stability, and resources, 
thereby threatening traditional channels and even whole business models [13]. Webb and Lambe's [12] study shows the potential conflict internal to the supplier firm among the groups and individuals responsible for managing the various channels. Anecdotal evidence suggests that channel members are negatively affected, for example, reports of HP's resellers clashing with HP over direct sales encroachment. One channel member, Repton, explained that "we are now nervous about engaging with certain HP people; they have taken business direct even though the deal was registered and approached some of our longest standing customers" [14].

Despite the growing evidence of manufacturer multichannel encroachment and the associated challenges and pressures, multiple channel systems have remained relatively under researched [15]. Recently several studies have been undertaken to understand different aspects of multiple channel systems and this initial research has called for more research on modelling the channel designs/mixes (e.g., $[12,13])$. Unlike previous research on durable goods which focuses on the marketing strategies of leasing and selling in a single-channel, however, we set up dual-channel models to understand how the addition of a manufacturer-owned e-channel impacts on the traditional marketing strategies of selling and leasing. The overall aim of this paper is therefore to examine the effects of manufacturer-owned e-channel choice on the traditional marketing channel strategies of selling and leasing, specifically accounting for the conditions-product durability, channel structure, and direct selling cost-under which firms choose a specific type of channel system. In particular, we intend to answer the following questions: How does the addition of an e-channel affect manufacturer's and reseller's (leasor's) performance? What is the implication of product durability and the channel structure on channel members' performance?

As such, our paper makes a number of contributions. The first is that this study makes an important contribution to the literature on dual-channel supply chains $[16,17]$. We build on the dual-channel supply chains literature, extending the analysis of horizontal competition under different channel structures, empirically linking the different channel boundary conditions of product durability, channel structure, and direct selling cost [17]. Specifically, our model extends and generalizes Arya et al.s [16] model to the durable goods setting [18-21]. Furthermore, we build on Heide's [22] study and related research [23] in modelling the impact of channel design/mix on performance. As Heide [22, p.27] notes, "the specific performance implications of plural systems remain unanswered. Establishing a link between particular governance approaches and outcome variables seems an important research priority." Our model indicates that, direct selling cost aside, product durability plays an important role in shaping the optimal strategies of all members. Second, we build on the early empirical evidence on vertical restraints which offers several efficiency-based explanations on the existence of exclusive territory agreements [7]. Significantly, our results show that the addition of an e-channel may secure Pareto gains, in which all members benefit from adding an e-channel, thus suggesting that a rising e-channel tide lifts all boats. Here we specify the nature of the efficiency gains, empirically linking them to different variables of interest. Third, we find that, to reduce the competition from her (throughout this paper, we use the feminine pronoun to refer to the manufacturer and the masculine pronoun to refer to the dealer (including the reseller and the leaser)) intermediaries, the manufacturer may set a higher wholesale price (a price skimming strategy) to the reseller (leaser) in Period 1 (Period 2) under a dual-channel supply chain. Although pricing is a major concern in channel strategies, it has received relatively little research attention. This study shows how price can be deployed as a heuristic device [24] as part of the manufacturers' marketing strategy in order to enjoy the benefits of adding an e-channel. Finally, we show that, bearing the brunt of the e-channel, leasing may dominate selling. We show how the addition of echannel brings Pareto gains, therefore adding to the literature which pays little attention to how this issue is affected by different marketing strategies (i.e., selling and leasing). This complements existing results that show that, unlike the optimum behavior of leasing by a durable goods monopolist, selling turns out to be the unique dominant strategy of the competing firms. Taken together, this lays the foundation for more specific research and analyses.

The remainder of the paper is organized as follows. Section 2 reviews the related literature and explains our contributions in more detail. Section 3 describes the key elements of our basic model and introduces notation. Section 4 outlines single-channel models and dual-channel models and reports our main findings. Section 5 concludes the paper.

\section{Relevant Literature}

Beginning with an analysis of time inconsistency (time inconsistency refers to a situation in which rational consumers, anticipating that the monopolist has an incentive to increase product availability and lower its price over time, postpone purchases until the price falls to a competitive level. This issue is formalized in Stokey [25]) by Coase [26], the relationship between leasing and selling has long been studied for durable goods. For example, Bulow [27], considering a monopolist who sells a perfectly durable good in a two-period market, shows that the monopolist can avoid the time inconsistency problem and has higher profitability by leasing. Desai and Purohit [28] explore the strategy of leasing and selling in a two-period model, finding that the relative profitability of leasing and selling hinges on the rates at which leased and sold units depreciate. Poddar [29] considers a simultaneous move game between two symmetric durable good firms and finds that selling turns out to be the unique dominant strategy of the firms. Bhaskaran and Gilbert [30] examine the possibility that if the manufacturer sells product, then the dealers can either sell or lease it to consumers and show that when the level of competition among dealers is high, the manufacturer prefers to lease rather than sell product to the dealers. Agrawal et al. [21] adopt a life-cycle environmental impact perspective and investigate whether leasing can both be more profitable and have a lower total environmental impact; they find that leasing can be environmentally worse (despite remarketing all off-lease products) and greener than 
selling (despite the mid-life removal of off-lease products) (for a thorough review of the literature on durable goods, see Waldman [31]). Andrikopoulos and Markellos [32] develop a model of dynamic interactions between price variations in leasing and selling markets for automobiles. Empirical analysis shows that variations in selling (cash) market prices lead to rapidly dissipating changes of leasing market prices in the opposite direction. Bhaskaran and Gilbert [33] explore the interactions between channel structure (direct interaction with consumers versus through intermediary(ies)) and mode of operations (leasing versus selling) and their implications for a manufacturer's willingness to invest in making her product more durable.

Although numerous researchers have focused on the marketing strategies of leasing and selling, most, if not all, studies traditionally assume that all goods are only distributed by dealers (i.e., resellers/leasers). However, with the investment in new technology, the manufacturers increasingly have the capacity of searching for business and active sales through manufacturer-owned e-channel [8]. Literature on vertical restraints offers several efficiency-based arguments for the existence of exclusive territory agreements, that is, not to search for business and active sales through manufacturer-owned e-channels. Most of these arguments relate to the incentives for the participants in the relationship and improved role performance and increase the manufacturer's commitment to the relationship $[7,12,13,34]$.

Related to these arguments is the literature on dualchannel supply chains, which advances two arguments. The first argues that the manufacturer direct selling results in channel conflict, harming relationships and hurting channel members' performance. Balasubramanian [35], for example, analyzes the potential for retail stores to bear the brunt of direct entry and uses market coverage as leverage to control conflict between direct marketer and retailer. Lee et al. [36] propose several practical guidelines for controlling the conflict in a dual-channel supply chain. Cattani et al. [37] liken a reseller facing manufacturer direct selling to the parable of boiling a frog: if the costs and average convenience of the manufacturer's e-channel become more favorable over time, then the manufacturer will be in a position to use the e-channel to undercut the prices in the traditional channel and so "boil" the reseller. Dan et al. [38] then show that retail services strongly influence the manufacturer and the retailer's pricing strategies. Betzabé and Aydın [39] characterize scenarios in which the manufacturer's and retailer's assortment preferences are in conflict. The result shows the manufacturer may prefer the retailer to carry items with high demand variability, while the retailer prefers items with low demand variability. Panda et al. [40] found that there is a severe price competition between the retail and online channel, and product compatibility has a significant impact on the pricing policy. The marketing literature has also analyzed some antecedents and consequences of vertical constraints, with antecedents ranging from the manufacturer's strategic brand positioning on quality (i.e., [41]), positive relationship between coordination and support efforts [3], the manufacturer's position in the distribution channel in relation to the competition existing in the manufacturers' market [42], and the provided distributor services that could be free-ridable by other channel members [3].

The second research stream, including Chiang et al. [43], Arya et al. [16], Dumrongsiri et al. [44], Cai [45], and Dan et al. [38], states that manufacturer encroachment brings Pareto gains and all channel members benefit from the encroachment. This efficiency-led approach proposes that echannel encroachment improves the role performance of all of the members companies and thereby the efficiency of the channel as a whole. In the marketing literature, studies find that exclusive territories agreements aim to create incentives system for parties in the channel relationship $[3,7]$, while a more anticompetitive led argument approach claims that exclusivity is used as a device to reduce competition and to extract monopoly rents from the market [46, 47].

While this research starts to inform, in part, our understanding of the questions, (i) how does the addition of an e-channel affect manufacturer's and reseller's (leasor's) performance? and (ii) what is the implication of product durability and the channel structure on channel members' performance?, we also need to build on this work in a number of important respects. First, model RE in this paper reduces to Arya et al. [16] when product durability goes to zero; thus it nests Arya et al. as a special case and generalizes it to the durable goods setting. Second, Xiong et al. [17] assume that the product is perfectly durable and does not deteriorate over time, and thus they cannot account for how product durability affects the interactions between a manufacturer and her dealers (including the reseller and the leaser). In contrast, we allow product deterioration over time and try to account for the strategic effects of product durability, channel structure, and direct selling cost, which can capture several characteristics salient in many of today's durable goods markets. Third, Xiong et al.s [17] focus on an environment of the dealer adopts a mix of selling and leasing. In contrast to Xiong et al.s [17], we instead investigate a much more common marketing setting, where selling and leasing are adopted by resellers and leasers, respectively and focus on how the addition of an e-channel affects different marketing strategies of selling and leasing.

\section{Model Development}

As in Arya et al. [16] and Xiong et al. [17], the sequence of the game between the manufacturer and the reseller is as follows: the manufacturer announces the wholesale price to the reseller (leaser) who then responds by determining the optimal units for selling (leasing). The manufacturer then chooses the units to be sold through the e-channel.

3.1. Product. To capture the durable nature of a product, we use a two-period model (a two-period model not only allows us to study dynamic issues while retaining tractability but also simplifies the presentation of our analysis (similar assumption is adopted by Desai and Purohit $[19,28]$ and Bhaskaran and Gilbert [30])) in which only new products are available in Period 1, but both new and used products (i.e., those "new" units marketed in Period 1 and then classified as "used" in Period 2) are available in Period 2. As in Desai and 
Purohit $[19,28]$, we designate the durability of the products produced in Period 1 using factor $\gamma(0 \leq \gamma \leq 1)$. If $\gamma=1$, the product is perfectly durable, meaning that, in Period 2, used units are identical to new units. If $\gamma=0$, the product is nondurable and deteriorates fully after one period of use.

3.2. Manufacturer Strategies. The manufacturer's problem is to maximize her profits by setting wholesale prices $\left(w_{i}\right)$ and choosing units $\left(q_{i m}\right)$ to sell through the e-channel. Here, $i=$ 1,2 denotes Period 1 or 2. As in Arya et al. [16] and Xiong et al. [17], for simplicity, we normalize her marginal cost of production to zero and assume that her marginal cost of selling on the e-channel is $C_{e}=c \geq 0$.

3.3. Reseller (Leaser) Strategies. The reseller (leaser) maximizes his profit by choosing $q_{i r}\left(q_{i l}\right)$. To ensure that the reseller (leaser) has an advantage in the distribution channel, like Arya et al. [16] and Xiong et al. [17], we assume that the reseller's (leaser's) unit marketing cost is $C_{r}=0\left(C_{l}=0\right)$.

3.4. Consumers. We derive the inverse demand functions from the consumer utility functions. We refer the reader to Desai and Purohit [28] and Agrawal et al. [21] for the detailed derivation. Let $l_{i j}$ be the price of the services provided by product $j$ in period $i$, where $j=n, u$ refers to, respectively, new products and used products. Then, the one-period prices for a new and a used product are given, respectively, by

$$
\begin{aligned}
& l_{1 n}=1-q_{1 r(l)}-q_{1 m}, \\
& l_{2 n}=1-\gamma\left(q_{1 r(l)}+q_{1 m}\right)-q_{2 r(l)}-q_{2 m}, \\
& l_{2 u}=\gamma\left(1-q_{1 r(l)}-q_{2 r(l)}-q_{1 m}-q_{2 m}\right) .
\end{aligned}
$$

Because it is "new" when a product is marketed in Period 1 and then is classified as "used" in Period 2, its selling price in Period 1 is $p_{1 n}=l_{1 n}+\rho l_{2 u}$, where $\rho$ is a discount factor denoting the cash flows received in Period 2. To simplify, we assume a zero discount rate and a discount factor $\rho=$ 1 (although allowing the discount factor $0<\rho<1$ increases the complexity of the analysis, all our results remain unaffected). Since the product produced in Period 2 provides only one period of service, there is no distinction between leasing and selling, and its selling price is $p_{2 n}=l_{2 n}$.

\section{Model Analysis}

In this section, we will outline single-channel models and dual-channel models and report our main findings.

4.1. Implications of the E-Channel on Selling. To analyze implications of the e-channel on the strategy of selling, we first look at model R (see Figure 1(a)) in which no e-channel is open and all products are sold through an independent reseller and then consider model RE (see Figure 1(b)) in which the manufacturer-owned e-channel opens.
4.1.1. Model R. From (1), the inverse demand functions in model $\mathrm{R}$ are as follows:

$$
\begin{aligned}
& P_{1 r}=l_{1 n}+l_{2 u}=1-q_{1 r}+\gamma\left(1-q_{1 r}-q_{2 r}\right), \\
& P_{2 r}=l_{2 n}=1-\gamma q_{1 r}-q_{2 r} .
\end{aligned}
$$

We use backward induction to determine the subgame perfect equilibrium. Specifically, the reseller maximized $\pi_{2}^{\mathrm{R}}=$ $\left(p_{2 r}-w_{2 r}\right) q_{2 r}$ (we use lowercase $\pi_{i}^{\mathrm{k}}$ and uppercase $\Pi_{i}^{\mathrm{k}}$ to represent the reseller's (leaser's) and manufacturer's profit in period $i$ under model $\mathrm{k}$ ) in Period 2 by choosing $q_{2 r}^{\mathrm{R} *}$. Working backwards, plugging $q_{2 r}^{\mathrm{R} *}$ into $\Pi_{2}^{\mathrm{R}}=w_{2 r} q_{2 r}$ and solving the first-order condition yield $w_{2 r}^{\mathrm{R} *}$.

Given the optimal solution for Period 2, we look at the decisions in Period 1. The reseller's problem is to maximize the total two-period profit, that is, $\pi^{\mathrm{R}}=\pi_{1}^{\mathrm{R}}+\pi_{2}^{\mathrm{R} *}=\left(p_{1 r}-\right.$ $\left.w_{1 r}\right) q_{1 r}+\pi_{2}^{\mathrm{R} *}$, by choosing $q_{1 r}^{\mathrm{R} *}$, and then the manufacturer maximizes the total two-period profit, $\Pi^{\mathrm{R}}=\Pi_{1}^{\mathrm{R}}+\Pi_{2}^{\mathrm{R} *}=$ $w_{1 r} q_{1 r}+\Pi_{2}^{\mathrm{R} *}$, by choosing $w_{1 r}^{\mathrm{R} *}$. We summarize both players' optimal decisions in Lemma A.1 in Appendix A. All proofs are provided in Appendix B.

4.1.2. Model RE. From (1), the purchase prices in Period 1 and Period 2 are

$$
\begin{aligned}
P_{1 r} & =l_{1 n}+l_{2 u} \\
& =1-q_{1 r}-q_{1 m}+\gamma\left(1-q_{1 r}-q_{2 r}-q_{1 m}-q_{2 m}\right), \\
P_{2 r} & =l_{2 n}=1-\gamma\left(q_{1 r}+q_{1 m}\right)-q_{2 r}-q_{2 m} .
\end{aligned}
$$

In model RE, the manufacturer can sell products through an e-channel; therefore, the manufacturer's problem is $\max _{q_{2 m}} \Pi_{2}^{\mathrm{RE}}=w_{2 r} q_{2 r}+p_{2 r} q_{2 m}-c q_{2 m}$. Given the manufacturer's optimal quantities $q_{2 m}^{\mathrm{RE} *}$, the reseller's problem is $\max _{q_{2 r}} \pi_{2}^{\mathrm{RE}}=p_{2 r} q_{2 r}-w_{2 r} q_{2 r}$. Observing the reseller's response $q_{2 r}^{\mathrm{RE} *}$, the manufacturer maximizes his profit $\left(\Pi_{2}^{\mathrm{RE}}\right)$ by choosing $w_{2 r}^{\mathrm{RE}}$.

In Period 1, each player's objective is to maximize the profit from both periods; that is,

$$
\begin{aligned}
& \max _{q_{1 m}, w_{1 r}} \Pi^{\mathrm{RE}}=w_{1 r} q_{1 r}+p_{1 r} q_{1 m}-c q_{1 m}+\Pi_{2}^{\mathrm{RE} *}, \\
& \max _{q_{1 r}} \pi^{\mathrm{RE}}=p_{1 r} q_{1 r}-w_{1 r} q_{1 r}+\pi_{2}^{\mathrm{RE} *} .
\end{aligned}
$$

Working backwards, we derive the optimal strategies of model RE in Lemma A.2 in Appendix A.

Arya et al's [16] outcome is identical to our result of model RE for the fully deteriorated product; that is, $\gamma=0$. Said differently, when product durability $\gamma=0$, the results in Lemma A.2 are consistent with that in Arya et al. [16]; therefore, our model nests theirs as a special case.

Based on Lemma A.2, we find several interesting characteristics about channel members' optimal strategies (see Figure 2).

Proposition 1. (a) In model RE, the manufacturer opens the $e$-channel if and only if $c<c_{1}(\gamma)$. 


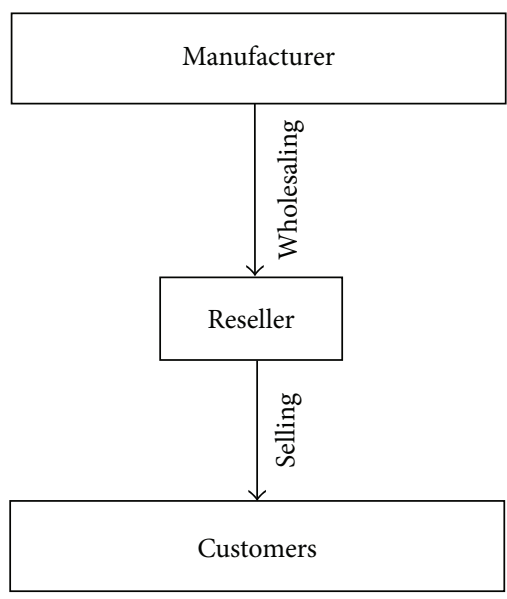

(a) Model R

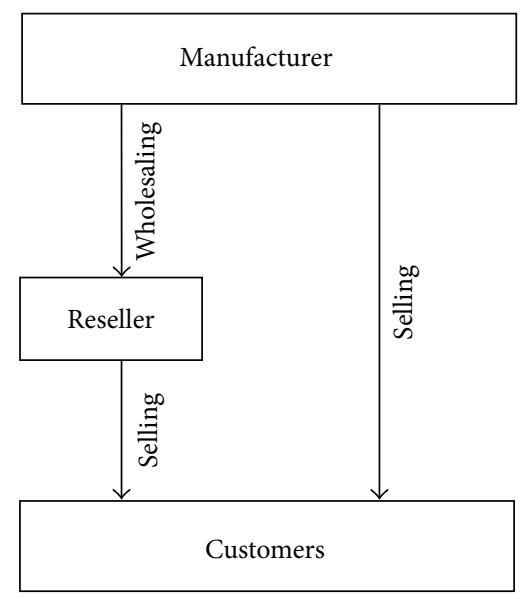

(b) Model RE

Figure 1: Model R and model RE.

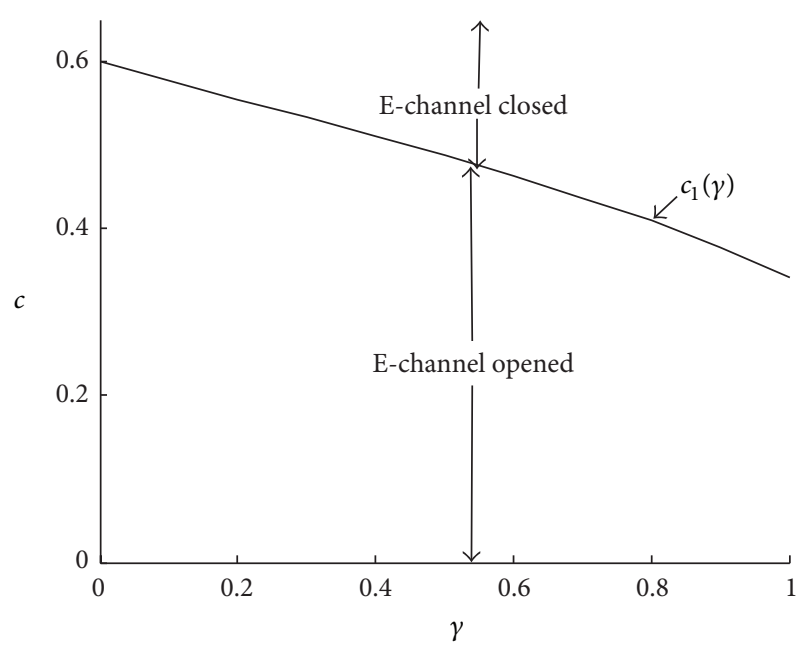

Figure 2: Optimal strategies under model RE.

(b) In model RE, when $c=0$, confronting the manufacturer encroachment, the reseller starts withdrawing from the market.

From Proposition 1, we find that when the direct selling disadvantage is not significant, the manufacturer encroaches into the reseller's market. This observation is partly consistent with that of Arya et al. [16] who conclude that "the manufacturer will encroach, if and only if its retail cost disadvantage is not too pronounced" (P. 654). However, we further find that durability plays an important role as well; for example, with product durability increases, the threshold $c_{1}(\gamma)$ decreases (see Figure 2).

4.1.3. Model $R$ versus Model RE. The following proposition summarizes the e-channel's effects on equilibrium outcomes.

Proposition 2. (a) The equilibrium quantities in model $R E$ are always higher than in model $R$; that is, $q_{2 r}^{R E}+q_{2 m}^{R E}>q_{2 r}^{R}$ and $q_{1 r}^{R E}+q_{1 m}^{R E}>q_{1 r}^{R}$. (b) In Period 2, the wholesale price in model RE is always lower than in model $R$; that is, $w_{2 r}^{R E}<w_{2 r}^{R}$; meanwhile in Period 1 , when $c<c_{2}(\gamma)$, the manufacturer sets a higher wholesale price in model RE than that in model $R$ (i.e., $w_{1 r}^{R E}>w_{1 r}^{R}$ ) but a lower wholesale price than model $R$ otherwise.

Proposition 2 shows that when the direct selling disadvantage $c$ is below $c_{2}(\gamma)$, the manufacturer sets a higher wholesale price in Period 1 under model RE. This can be interpreted as follows: $c<c_{2}(\gamma)$ means that the direct selling disadvantage is insignificant and the competition between the reseller channel and manufacturer-owned e-channel is intense, which results in the fact that the manufacturer sets a higher wholesale price to reduce the competition from the reseller. Another interesting characteristic of the above proposition is that the manufacturer may set a lower wholesale price in model RE, an observation supported by Xiong et al. [17] and Arya et al. [16]. For example, Arya et al. [16] conclude that "if this competitive advantage were not counterbalanced by a lower wholesale price, the advantage would reduce the output of the incumbent retailer unduly and thereby reduce its demand for the essential input" (P. 654).

We now look at the difference in the profits under model $\mathrm{R}$ and model RE and our analysis suggests the following proposition (see Figure 3).

Proposition 3. (a) The manufacturer is always better off in model RE than in model $R$; that is, $\Pi^{R E}>\Pi^{R}$.

(b) When $c>c_{3}(\gamma)$, the reseller's profit in model $R E$ is higher than in model $R$; that is, $\pi^{R E}>\pi^{R}$; otherwise, the opposite is true.

(c) When $c_{4}(\gamma)<c<c_{1}(\gamma)$ or $0<c<c_{5}(\gamma)$, the supply chain profit in model RE is higher than that in model $R$; that is, $\Pi_{T}^{R E}>\Pi_{T}^{R}$; otherwise, the opposite is true.

Proposition 3 shows that when $c>c_{3}(\gamma)$, the direct selling disadvantage is pronounced; the competition from the manufacturer encroachment can be overcome by the reduction in the wholesale prices. As a result, the reseller can 


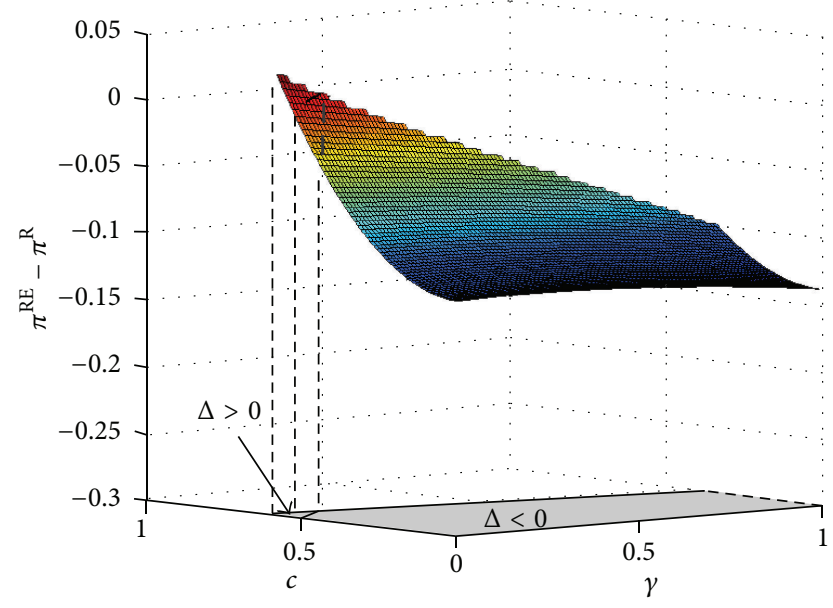

(a)

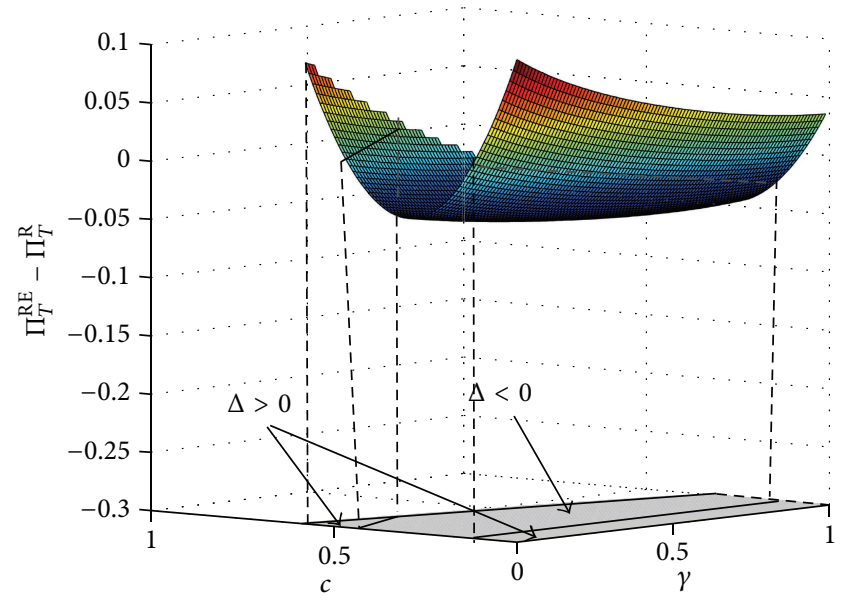

(b)

FIguRE 3: $\pi^{\mathrm{RE}}-\pi^{\mathrm{R}}$ and $\Pi_{T}^{\mathrm{RE}}-\Pi_{T}^{\mathrm{R}}$.

benefit from the manufacturer encroachment. Proposition 3 also shows that either when the direct selling disadvantage is sufficiently pronounced (i.e., $c_{4}(\gamma)<c<c_{1}(\gamma)$ ) or when it is insignificant (i.e., $0<c<c_{5}(\gamma)$ ), the manufacturer's direct selling increases the supply chain profit. The intuition behind this is that when $0<c<c_{5}(\gamma)$, the direct selling disadvantage is so insignificant that the competition from the reseller is limited. As a result, the manufacturer's profit increasing is substantial, which overcomes the loss of the reseller's profit. Said differently, the direct selling can enhance supply chain profit even when it reduces the reseller's profit. On the other hand, when $c_{4}(\gamma)<c<c_{1}(\gamma)$, the manufacturer's direct selling can secure Pareto gains: the manufacturer obtains more profit by direct selling and the reseller benefits from the wholesale price decreasing.

We note that Arya et al. [16] also conclude that "when the retailer's cost advantage is sufficiently pronounced, the retailer benefits from encroachment." And "encroachment will increase the supply chain profit either when the retailer's downstream cost advantage is sufficiently pronounced or when it is sufficiently limited" (P. 654). We further find, however, that durability plays an important role; for example (see Figure 3), with product durability increases, the thresholds of $c_{3}(\gamma)$ and $c_{4}(\gamma)$ increase, but $c_{5}(\gamma)$ decreases.

4.2. Implications of the E-Channel on Leasing. To analyze implications of the e-channel on the strategy of leasing, we first look at model L (see Figure 4(a)), in which no e-channel is open and all products are leased through an independent leaser, and then consider model LE (see Figure 4(b)), in which the manufacturer-owned e-channel opens.

4.2.1. Model L. From (1), the inverse demand functions in model $\mathrm{L}$ are as follows:

$$
\begin{aligned}
& l_{1 n}=1-q_{1 l}, \\
& l_{2 n}=1-\gamma q_{1 l}-q_{2 l}, \\
& l_{2 u}=\gamma\left(1-q_{1 l}-q_{2 l}\right) .
\end{aligned}
$$

In Period 2, the leaser's problem is to choose optimal quantities $\left(q_{2 l}^{\mathrm{L} *}\right)$ to maximize his profits; $\pi_{2}^{\mathrm{L}}=\left(l_{2 n}-w_{2 l}\right) q_{2 l}+$ $l_{2 u} q_{1 l}$. Given optimal $q_{2 l}^{\mathrm{L} *}$, the manufacturer optimizes profits by choosing $w_{2 l}^{\mathrm{L} *}$, that is, by maximizing $\Pi_{2}^{\mathrm{L}}=w_{2 l} q_{2 l}$.

In Period 1 , the leaser's problem is to maximize the total two-period profit, that is, $\pi^{\mathrm{L}}=\pi_{1}^{\mathrm{L}}+\pi_{2}^{\mathrm{L} *}=\left(l_{1 n}-w_{1 l}\right) q_{1 l}+\pi_{2}^{\mathrm{L} *}$, by choosing $q_{1 l}^{\mathrm{L} *}$, and then the manufacturer maximizes the total two-period profits, $\Pi^{\mathrm{L}}=\Pi_{1}^{\mathrm{L}}+\Pi_{2}^{\mathrm{L} *}=w_{1 l} q_{1 l}+\Pi_{2}^{\mathrm{L} *}$, by choosing $w_{1 l}^{\mathrm{L} *}$. Using backward induction again, we get Lemma A.3 in Appendix A.

4.2.2. Model LE. We now analyze model LE, in which the manufacturer sells the products through both a manufacturer-owned e-channel and an independent leaser who then leases the products to consumers.

From (1), the purchase prices in Period 1 and Period 2 are

$$
\begin{aligned}
l_{1 n} & =1-q_{1 l}-q_{1 m}, \\
l_{2 n} & =1-\gamma\left(q_{1 l}+q_{1 m}\right)-q_{2 l}-q_{2 m}, \\
l_{2 u} & =\gamma\left(1-q_{1 l}-q_{2 l}-q_{1 m}-q_{2 m}\right), \\
P_{1 r} & =l_{1 n}+l_{2 u} \\
& =1-q_{1 l}-q_{1 m}+\gamma\left(1-q_{1 l}-q_{2 l}-q_{1 m}-q_{2 m}\right), \\
P_{2 r} & =l_{2 n}=1-\gamma\left(q_{1 l}+q_{1 m}\right)-q_{2 l}-q_{2 m} .
\end{aligned}
$$

In model LE, the manufacturer's problems in Period 2 and Period 1, respectively, are

$$
\begin{aligned}
& \max _{q_{2 m}, w_{2 l}} \Pi_{2}^{\mathrm{LE}}=w_{2 l} q_{2 l}+p_{2 r} q_{2 m}-c q_{2 m}, \\
& \max _{q_{1 m}, w_{1 l}} \Pi^{\mathrm{LE}}=w_{1 l} q_{1 l}+p_{1 r} q_{1 m}-c q_{1 m}+\Pi_{2}^{\mathrm{LE} *} .
\end{aligned}
$$




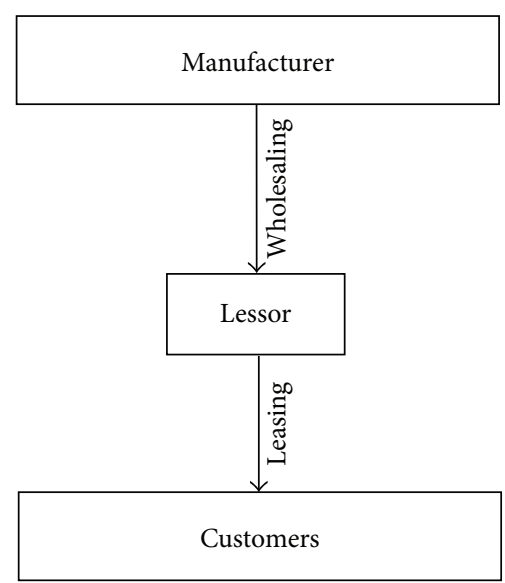

(a) Model L

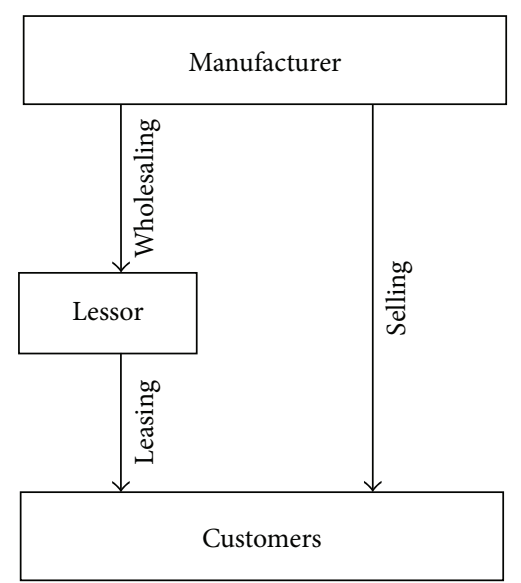

(b) Model LE

FIgure 4: Model L and model LE.

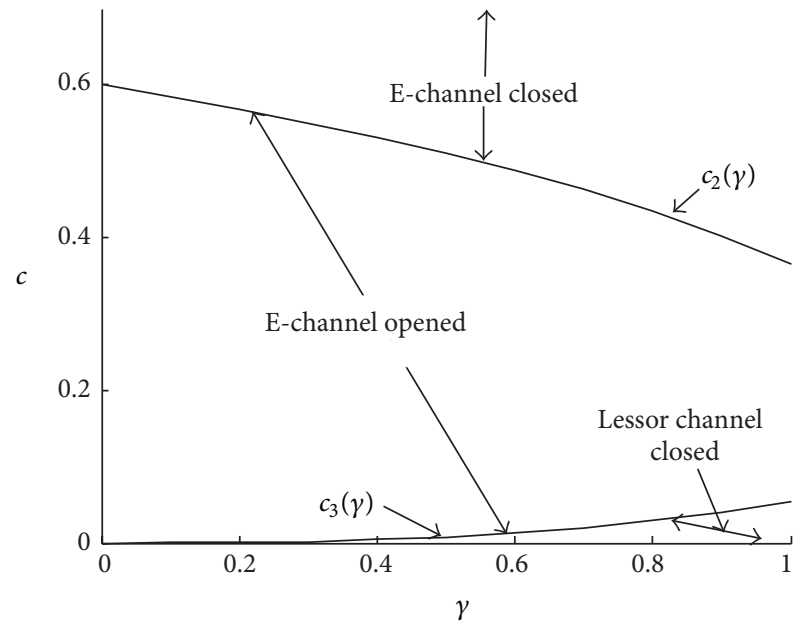

FIgURE 5: Optimal strategies under model LE.

The leaser's problems are

$$
\begin{aligned}
& \max _{q_{2 l}} \pi_{2}^{\mathrm{LE}}=l_{2 n} q_{2 l}+l_{2 u} q_{1 l}-w_{2 l} q_{2 l}, \\
& \max _{q_{1 l}} \pi^{\mathrm{LE}}=l_{1 n} q_{1 l}-w_{1 l} q_{1 l}+\pi_{2}^{\mathrm{LE} *} .
\end{aligned}
$$

Using backward induction, we derive the optimal strategies of model LE in Lemma A.4 in Appendix A.

Based on Lemma A.4, we have the following proposition (see Figure 5).

Proposition 4. (a) In model LE, the manufacturer opens the e-channel if and only if $c<c_{6}(\gamma)$.

(b) In model $L E$, when $c \leq c_{7}(\gamma)$, confronting the manufacturer encroachment, the leaser starts withdrawing from the market in Period 2.
Similar to Proposition 1, we find that when the direct selling disadvantage is not significant, the manufacturer encroaches into the leaser's market. However, we further find that, in model LE, with product durability increases, the threshold at which the leaser starts withdrawing from the market increases. Meanwhile in model RE, similar to that of Arya et al. [16], the threshold for the reseller starting withdrawing from the market is $c=0$. Figure 5 illustrates these results.

4.2.3. Model L versus Model LE. As before, we look first at the effects of the e-channel on equilibrium outcomes under both models.

Proposition 5. (a) The equilibrium quantities in model LE are always higher than in model $L$; that is, $q_{2 l}^{L E}+q_{2 m}^{L E}>q_{2 l}^{L}$ and $q_{1 l}^{L E}+q_{1 m}^{L E}>q_{11}^{L}$.

(b) In Period 1, the wholesale price in model LE is always lower than in model L; that is, $w_{1 l}^{L E}<w_{1 l}^{L}$; meanwhile in Period 2 , when $c<c_{8}(\gamma)$, the manufacturer sets a higher wholesale price in model LE but a lower wholesale price than in model $L$ otherwise.

Proposition 5 shows that, in contrast to model RE, in which the manufacturer may set a higher wholesale price in Period 1, the manufacturer here always sets a lower wholesale price in Period 1, while she may provide a higher wholesale price in Period 2. The reason for this reversal is that, in Period 2 , for the manufacturer, the impacts from the strategies of leasing and selling are identical, because Period 2 is the last period of the market and all new products provide one-period use. Note that, in Period 1, the wholesale price in model LE is lower than in model L (i.e., $\left.w_{1 l}^{\mathrm{LE}}<w_{1 l}^{\mathrm{L}}\right)$. To "compensate" for the profit "loss" in Period 1 and to reduce the competition from the leaser, the manufacturer sets a higher wholesale price in Period 2.

We now look at the difference in profits under model $\mathrm{L}$ and model LE (see Figure 6). 


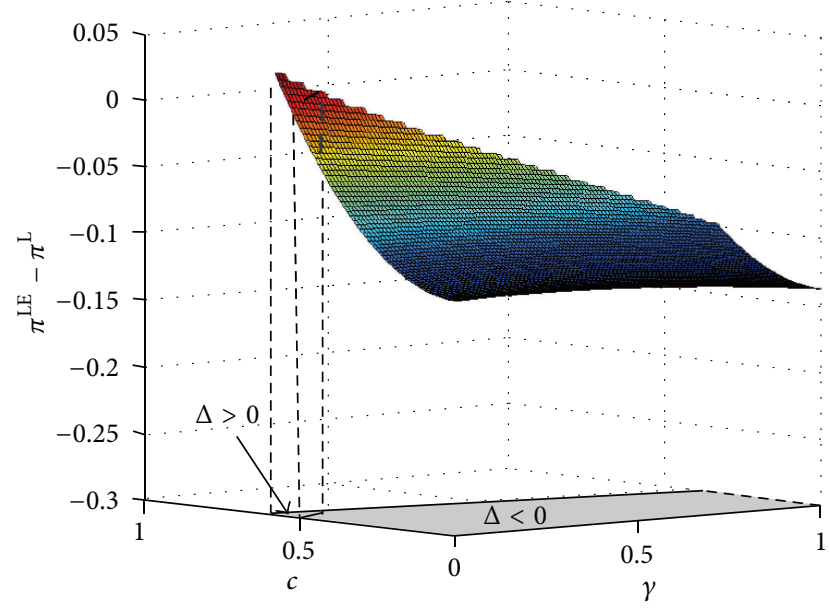

(a)

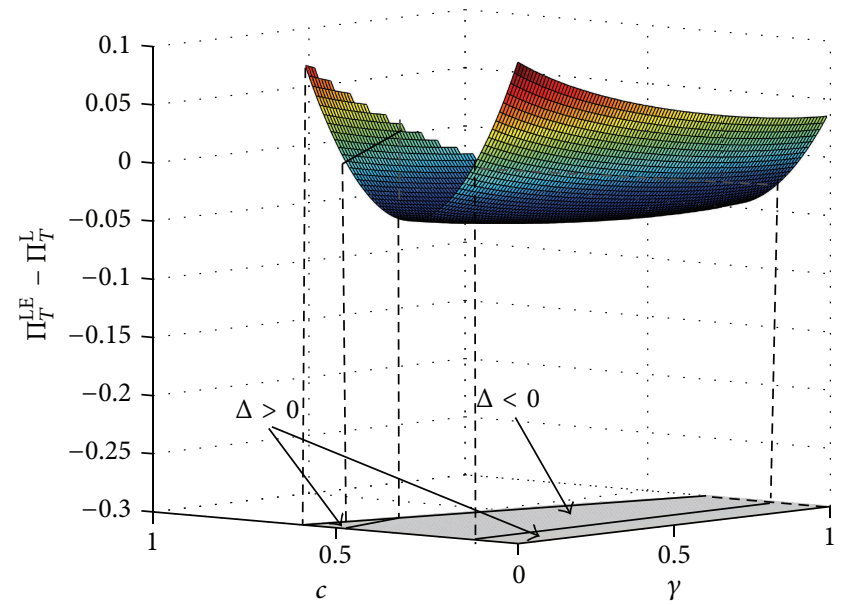

(b)

FIGURE 6: $\pi^{\mathrm{LE}}-\pi^{\mathrm{L}}$ and $\Pi_{T}^{\mathrm{LE}}-\Pi_{T}^{\mathrm{L}}$.

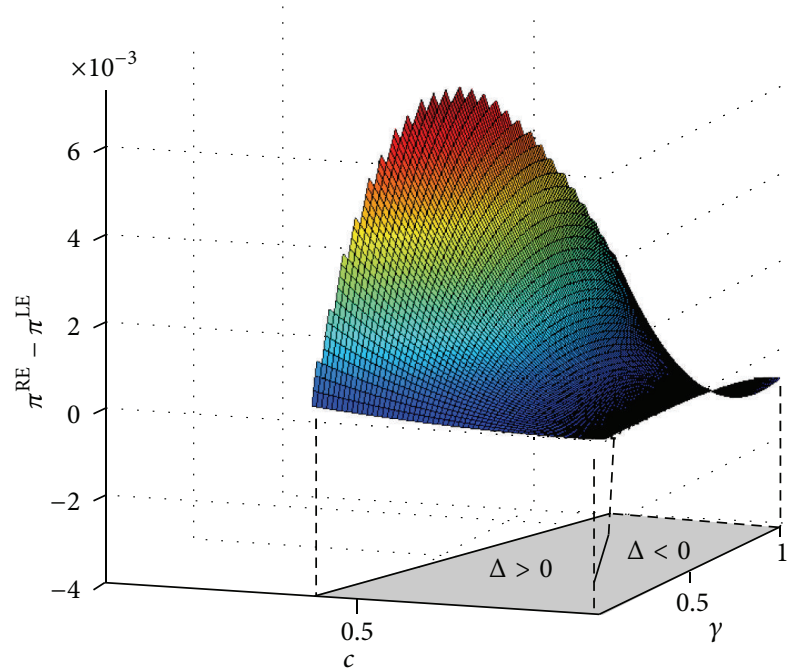

(a)

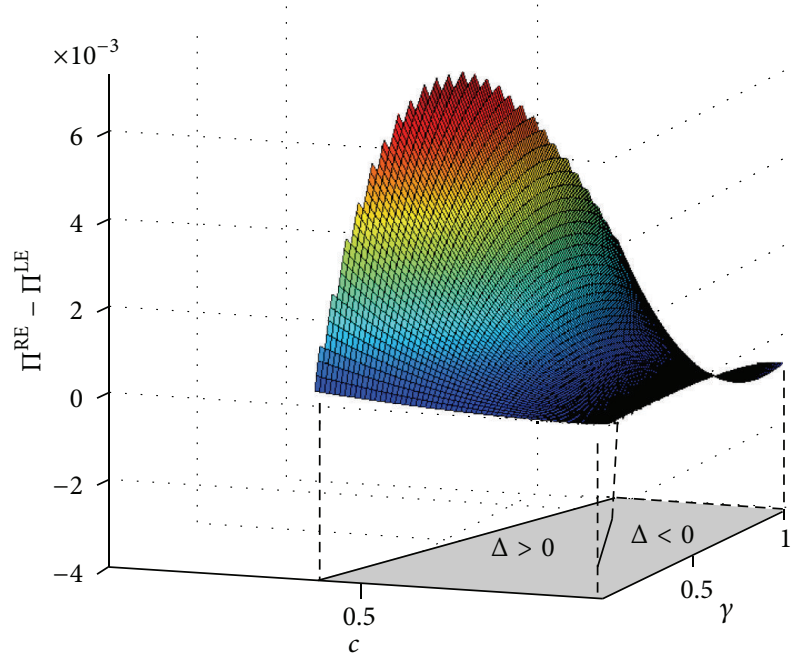

(b)

Figure 7: $\pi^{\mathrm{RE}}-\pi^{\mathrm{LE}}$ and $\Pi^{\mathrm{RE}}-\Pi^{\mathrm{LE}}$.

Proposition 6. (a) The manufacturer is always better off in model LE than in model $L$; that is, $\Pi^{L E}>\Pi^{L}$.

(b) When $c>c_{9}(\gamma)$, the reseller's profit in model LE is higher than in model $L$; that is, $\pi^{L E}>\pi^{L}$; otherwise, the opposite is true.

(c) When $c_{10}(\gamma)<c<c_{6}(\gamma)$ or $0<c<c_{11}(\gamma)$, the supply chain profit in model LE is higher than that in model $L$; otherwise, the opposite is true.

Obviously, similar to Proposition 3, the above proposition shows that, under certain conditions, the manufacturer encroachment may achieve Pareto gains.

4.3. Comparing Implications on Selling and Leasing. In this section, we provide insights into different implications of the e-channel on marketing strategies of selling and leasing.
Based on Lemmas A.2 and A.4, we first compare all parties' performances under model RE and model LE (see Figure 7).

Proposition 7. (a) If $c<c_{12}(\gamma)$, the leaser has a higher profit than the reseller; that is, $\pi^{L E}>\pi^{R E}$; otherwise, the opposite is true.

(b) If $c<c_{12}(\gamma)$, the manufacturer is better off in model LE; that is, $\Pi^{L E}>\Pi^{R E}$; otherwise, the opposite is true.

Before explaining Proposition 7, we must briefly analyze the manufacturer's profit, in dual-channel models, which comes from two sources: wholesaling products to the reseller (leaser) and selling through her own e-channel. And recalling that because of retaining ownership of the products to mitigate the cannibalization problem between used and new 


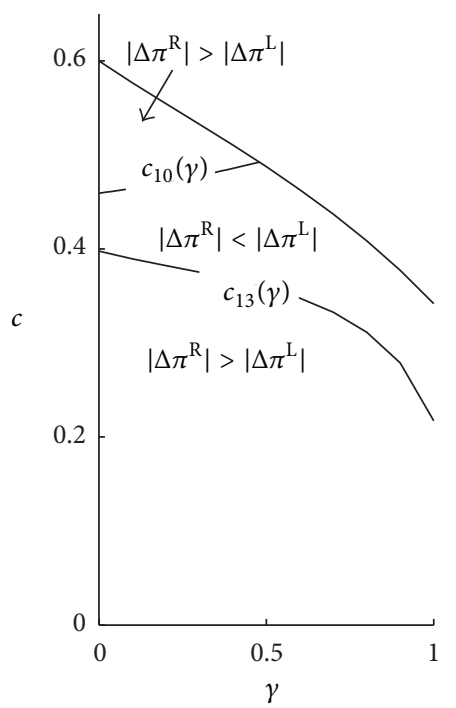

(a)

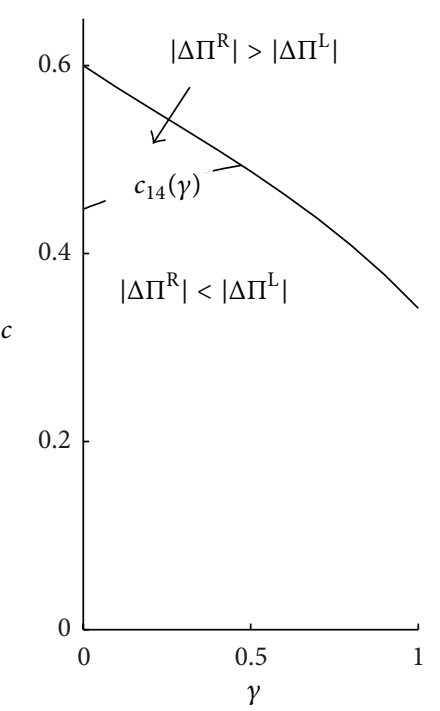

(b)

FIGURE 8: Variations in the profits.

goods the leaser is more likely to provide a smaller quantity of units than the reseller.

Proposition 7 can thus be interpreted as follows: anticipating that the leaser provides a smaller quantity of units than the reseller, the manufacturer sets a higher wholesale price for the reseller than that for the leaser. She does so for two reasons. First, anticipating that the leaser is more likely to provide a smaller quantity of units than the reseller (which means that the manufacturer's potential market is larger and the marginal revenues in the retail channel are higher) the manufacturer sets a lower wholesale price to show "appreciation" for the leaser's "coordination" and to avoid reducing the leaser's profit unduly. Second, because the reseller sells a higher quantity of units, in order to reduce the competition from the reseller and to have a larger potential market, the manufacturer sets a higher wholesale price to him. As a result, compared with the reseller's selling, the leaser's leasing achieves a win-win result: the manufacturer obtains more profit by direct selling and the leaser benefits from the wholesale price decreasing.

Contrary to the conventional wisdom, "in a competition situation, selling turns out to be the unique dominant strategy of the firms" (see Ausubel and Deneckere [48], Von der Fehr and Kühn [49], Biehl [50], and Poddar [29] for related results), Proposition 7 implies that under certain conditions, bearing the brunt of the e-channel, leasing dominates selling. We believe this difference stems from our focus on the competition between the upstream manufacturer and the downstream dealer rather than the competition between two manufacturers. On the other hand, our observation differs from those of Bucovetsky and Chilton [51] and Xiong et al. [17] who argued that "in presence of threat of entry, an optimal pre-entry contract is a mix of renting and selling," a difference that we do not allow; the dealer chooses both renting and selling together.

We are now in a position to address the question posed at the beginning of this paper: how does the addition of an e-channel affect manufacturer's and reseller's (leaser's) performance? To answer this question, we need to compare the variations in all parties' profitability under model $\mathrm{R}$ and model RE with those under model $\mathrm{L}$ and model LE. For simplicity, we use $\Delta \pi^{\mathrm{R}(\mathrm{L})}=\pi^{\mathrm{RE}(\mathrm{LE})}-\pi^{\mathrm{R}(\mathrm{L})}$ and $\Delta \Pi^{\mathrm{R}(\mathrm{L})}=$ $\Pi^{\mathrm{RE}(\mathrm{LE})}-\Pi^{\mathrm{R}(\mathrm{L})}$ to denote the variations in the reseller's (leaser's) and manufacturer's profitability under strategies of selling and leasing, respectively.

Based on Lemmas A.1, A.2, A.3, and A.4, we answer the above question as follows (see Figure 8).

Proposition 8. (a) When $c_{13}(\gamma)<c<c_{10}(\gamma)$, the manufacturer's direct selling adds more pressure on leasing (i.e., $\left.\left|\Delta \pi^{L}\right|>\left|\Delta \pi^{R}\right|\right)$; otherwise, the e-channel provides more pressure on selling; that is, $\left|\Delta \pi^{R}\right|>\left|\Delta \pi^{L}\right|$.

(b) When $c<c_{14}(\gamma)$, the manufacturer benefits more on leasing than on selling by adding an e-channel (i.e., $\left|\Delta \Pi^{L}\right|>$ $\left.\left|\Delta \Pi^{R}\right|\right)$; otherwise, the opposite is true.

The conventional wisdom suggests that, because the leasers retain ownership of the products for themselves, which means manufacturer's direct selling not only impacts the leasers' revenue from the new products but also affects the revenues from the ex-leased units. As a result, the manufacturer's direct selling adds more pressure on its leasers. Said differently, the manufacturer-owned e-channel is more harmful to leasing than to selling. This logic, though, misses a key point: the manufacturer can alter her preferred wholesale price.

Proposition 8 shows that (see Figure 8) when $c<c_{13}(\gamma)$, the e-channel provides more pressure on selling and hurts the reseller more than the leaser. This is because in order to reduce the competition from the reseller and to have a larger potential market the manufacturer sets a higher wholesale price to him. Said differently, the selling achieves more difficult position to the reseller, because he not only 
needs to compete with the products from e-channel but also needs to bear higher wholesale prices than leaser.

Proposition 8 also shows that (see Figure 8) when $c<$ $c_{14}(\gamma)$, the manufacturer benefits more on leasing than on selling by adding an e-channel; otherwise, the opposite is true. The reason behind this is as follows. Indeed when $c<$ $c_{14}(\gamma)$, as explanation of Proposition 7 shows, the leaser's leasing achieves a win-win result: the manufacturer obtains more profit by direct selling and the leaser benefits from the wholesale price decreasing. However, when $c>c_{14}(\gamma)$, most of the manufacturer's profit drives from wholesaling; the manufacturer can benefit from selling compared to leasing, because the reseller provides more quantity of products to consumers; that is, $\left|\Delta \Pi^{R}\right|>\left|\Delta \Pi^{L}\right|$.

\section{Conclusion}

Organizing and managing channels of distribution is an important marketing activity for manufacturers. Due to the emergence of electronic commerce on the Internet, e-channel distribution systems have been adopted by many manufacturers. However, this has not been without many complications within and across distribution channel systems. Although the marketing issues associated with leasing and selling have been well studied in the literature on durable goods, little is known about how these marketing strategies are impacted by manufacturers' adoption of e-channels and a more direct selling approach to the market. To fill this void, we develop a two-period model to investigate how the addition of a manufacturer e-channel impacts on the strategies of selling and leasing.

Our model extends and generalizes Arya et al.'s [16] model to the durable goods setting. Specifically, we develop twoperiod models, in which a manufacturer sells a durable product directly through both a manufacturer-owned e-channel and an independent reseller (leaser) who adopts a strategy of selling (leasing) to consumers to account for the strategic effects of product durability, channel structure, and direct selling cost. Our model thus captures several characteristics salient in many of today's durable goods markets.

We find that, direct selling cost aside, product durability plays an important role in shaping the optimal strategies of all members. As in Arya et al. [16] and Xiong et al. [17], our results also show that the addition of an e-channel may secure Pareto gains, in which all members benefit from adding an e-channel to the single-channel supply chain. Among other results, we find that, to reduce the competition from her intermediaries, the manufacturer may set a higher wholesale price to the reseller (leaser) in Period 1 (Period 2). Moreover, contrary to Ausubel and Deneckere [48], Von der
Fehr and Kühn [49], Biehl [50], and Poddar [29], "unlike the optimum behavior of leasing by a durable goods monopolist, selling turns out to be the unique dominant strategy of the competing firms," we show that, bearing the brunt of the echannel, leasing may dominate selling.

We acknowledge the limitations of our model. First, such assumptions as the monopoly manufacturer, complete information, and no service competition could be relaxed. Second, the reseller (leaser) sells (leases) to consumers at brickand-mortar stores, an assumption that although common in the literature of dual-channel supply chain (e.g., Tsay and Agrawal [52], Arya et al. [16], Chen et al. [53], and Xiong et al. [17]) does not reflect the reality that many resellers have ventured into the online world. Third, we assume that the e-channel only distributed new products at a normal price, whereas, in reality, the use of e-channel also serves the purpose of being a secondary market (Ning et al. [54], e.g., addressed that a retailer could consider introducing emarketplace to dispose of the excess inventory and found that the expected profit and risk in the supply chain are both increased when e-marketplace is introduced).

\section{Appendix}

\section{A. Four Lemmas}

Lemma A.1. In model $R$, the equilibrium quantities, wholesale price, and profits, respectively, are

$$
\begin{aligned}
q_{2 r}^{R *} & =\frac{15 \gamma^{2}-24 \gamma-32}{16\left(3 \gamma^{2}-8 \gamma-8\right)}, \\
w_{2 r}^{R *} & =\frac{15 \gamma^{2}-24 \gamma-32}{24 \gamma^{2}-64 \gamma-64}, \\
q_{1 r}^{R *} & =\frac{3 \gamma+8}{32 \gamma+32-12 \gamma^{2}}, \\
w_{1 r}^{R *} & =\frac{45 \gamma^{3}-240 \gamma-128-56 \gamma^{2}}{32\left(3 \gamma^{2}-8 \gamma-8\right)}, \\
\pi^{R *} & =\frac{99 \gamma^{4}+848 \gamma^{2}+3840 \gamma+2048-864 \gamma^{3}}{256\left(3 \gamma^{2}-8 \gamma-8\right)^{2}}, \\
\Pi^{R *} & =\frac{15 \gamma^{2}-112 \gamma-128}{64\left(3 \gamma^{2}-8 \gamma-8\right)} .
\end{aligned}
$$

Lemma A.2. In model RE, the equilibrium quantities, wholesale price, and profits, respectively, are

$$
\begin{aligned}
& q_{2 m}^{R E *}=\frac{9 \gamma^{4}-11 c \gamma^{4}+42 c \gamma^{3}-24 \gamma^{3}+6 c \gamma^{2}-18 \gamma^{2}+36 \gamma-76 c \gamma-40 c+24}{18 \gamma^{4}-60 \gamma^{3}-12 \gamma^{2}+96 \gamma+48}, \\
& q_{2 r}^{R E *}=\frac{2 c}{3}, \\
& w_{2 r}^{R E *}=\frac{c \gamma^{4}+9 \gamma^{4}-24 \gamma^{3}+2 c \gamma^{3}-2 c \gamma^{2}-18 \gamma^{2}-12 c \gamma+36 \gamma+24-8 c}{18 \gamma^{4}-60 \gamma^{3}-12 \gamma^{2}+96 \gamma+48},
\end{aligned}
$$




$$
\begin{aligned}
& q_{1 m}^{R E *}=\frac{24 \gamma^{3}+40 c+64 c \gamma+34 c \gamma^{4}-44 c \gamma^{2}-52 c \gamma^{3}-4 \gamma^{5} c-24-48 \gamma-6 \gamma^{4}}{3\left(\gamma^{2}-2 \gamma-2\right)^{2}(3 \gamma+2)(\gamma-2)}, \\
& q_{1 r}^{R E *}=\frac{2 c(3 \gamma+2)(2-\gamma)}{3\left(\gamma^{2}-2 \gamma-2\right)^{2}}, \\
& w_{1 r}^{R E *}=\frac{9 \gamma^{3}+8 c \gamma+4 c-c \gamma^{3}-2 c \gamma-24 \gamma-12}{18 \gamma^{2}-24 \gamma-24}, \\
& \pi^{R E *}=\frac{2\left(\gamma^{4}-4 \gamma^{3}-3 \gamma^{2}+12 \gamma+8\right) c^{2}}{9\left(\gamma^{2}-2 \gamma-2\right)^{2}}, \\
& \Pi^{R E *}=\frac{1}{36}\left(27 \gamma^{6}+72 \gamma^{4}+47 c^{2} \gamma^{6}-54 c \gamma^{6}-224 \gamma^{5} c^{2}+240 \gamma^{5} c-144 \gamma^{5}-84 c^{2} \gamma^{4}-720 \gamma+48 c \gamma^{4}+504 \gamma^{3}-1008 c \gamma^{3}\right. \\
& \left.\quad+1144 c^{2} \gamma^{3}-24 c \gamma^{2}-4 c^{2} \gamma^{2}-180 \gamma^{2}-1488 c^{2} \gamma+1248 c \gamma-672 c^{2}-288+576 c\right)\left(3 \gamma^{2}-4 \gamma-4\right)^{-1}\left(\gamma^{2}-2 \gamma-2\right)^{-2} .
\end{aligned}
$$

Lemma A.3. In model L, the equilibrium quantities, wholesale price, and profits, respectively, are

$$
\begin{aligned}
& q_{2 l}^{L *}=\frac{5 \gamma^{2}-4 \gamma-8}{16\left(\gamma^{2}-2-2 \gamma\right)}, \\
& w_{2 l}^{L *}=\frac{5 \gamma^{2}-4 \gamma-8}{8\left(\gamma^{2}-2-2 \gamma\right)}, \\
& q_{1 l}^{L *}=\frac{\gamma+4}{8\left(2 \gamma+2-\gamma^{2}\right)},
\end{aligned}
$$

$$
\begin{aligned}
w_{1 l}^{L *} & =\frac{11 \gamma^{3}-36 \gamma-8 \gamma^{2}-16}{16\left(\gamma^{2}-2 \gamma-2\right)}, \\
\pi^{L *} & =\frac{15 \gamma^{4}+224 \gamma+128-68 \gamma^{3}+20 \gamma^{2}}{256\left(\gamma^{2}-2-2 \gamma\right)^{2}}, \\
\Pi^{L *} & =\frac{\left(7 \gamma^{2}-24 \gamma-32\right)}{64\left(\gamma^{2}-2-2 \gamma\right)} .
\end{aligned}
$$

Lemma A.4. In model LE, the equilibrium quantities, wholesale price, and profits, respectively, are

$$
\begin{aligned}
& q_{2 m}^{L E *}=\frac{1}{6}\left(1032 \gamma^{5}-207 \gamma^{6}+237 c \gamma^{6}-1378 \gamma^{5} c+1092 c \gamma^{4}-408 \gamma^{4}+4232 \gamma^{3} c-3108 \gamma^{3}+420 \gamma^{2}-2252 \gamma^{2} c-5976 \gamma c\right. \\
&+3240 \gamma+1296-2160 c)(3 \gamma+2)^{-1}(2-\gamma)^{-1}\left(23 \gamma^{2}-54 \gamma-54\right)^{-1}\left(\gamma^{2}-2 \gamma-2\right)^{-1}, \\
& q_{2 l}^{L E *}=\frac{2\left(15 c \gamma^{4}-62 \gamma^{3} c-3 \gamma^{3}-20 \gamma^{2} c+180 \gamma c+108 c\right)}{3\left(23 \gamma^{2}-54 \gamma-54\right)\left(\gamma^{2}-2 \gamma-2\right)}, \\
& w_{2 l}^{L E *}= \frac{57 \gamma^{4} c-207 \gamma^{4}-280 \gamma^{3} c+654 \gamma^{3}+134 \gamma^{2} c+438 \gamma^{2}-972 \gamma+468 \gamma c+216 c-648}{6\left(23 \gamma^{2}-54 \gamma-54\right)(3 \gamma+2)(2-\gamma)}, \\
& q_{1 m}^{L E *}= \frac{2\left(102 \gamma^{5} c-583 \gamma^{4} c+90 \gamma^{4}+692 \gamma^{3} c-318 \gamma^{3}+720 \gamma^{2} c+6 \gamma^{2}+648 \gamma-816 \gamma c+324-540 c\right)}{3(3 \gamma+2)(2-\gamma)\left(23 \gamma^{2}-54 \gamma-54\right)\left(\gamma^{2}-2 \gamma-2\right)}, \\
& q_{1 l}^{L E *}= \frac{2\left(8 \gamma^{3} c-38 \gamma^{2} c+3 \gamma^{2}+28 \gamma c+36 c\right)}{\left(23 \gamma^{2}-54 \gamma-54\right)\left(\gamma^{2}-2 \gamma-2\right)}, \\
& w_{1 l}^{L E *}= \frac{1}{18}\left(357 \gamma^{7} c+621 \gamma^{7}-2592 \gamma^{6}-2250 \gamma^{6} c-1848 \gamma^{5}+3328 \gamma^{5} c+12228 \gamma^{4}+2684 \gamma^{4} c+6804 \gamma^{3}-6044 \gamma^{3} c\right. \\
&\left.-1944 \gamma^{2} c-15408 \gamma^{2}-15552 \gamma+3168 \gamma c+1296 c-3888\right)(\gamma-2)^{-1}(3 \gamma+2)^{-1}\left(23 \gamma^{2}-54 \gamma-54\right)^{-1}\left(\gamma^{2}-2 \gamma-2\right)^{-1},
\end{aligned}
$$




$$
\begin{aligned}
& \pi^{L E *}=\frac{2}{9}\left(474816 \gamma^{4} c^{2}-9360 \gamma^{7} c+306 \gamma^{7}-18 \gamma^{6}-648 \gamma^{5}-324 \gamma^{4}-432 \gamma^{9} c+3684 \gamma^{8} c+9560 \gamma^{8} c^{2}+76840 \gamma^{7} c^{2}\right. \\
& -186832 \gamma^{6} c^{2}-130848 \gamma^{5} c^{2}+1011 \gamma^{10} c^{2}-8268 \gamma^{9} c^{2}-81 \gamma^{8}+255456 \gamma^{3} c^{2}-422640 \gamma^{2} c^{2}-399168 \gamma c^{2}-93312 c^{2} \\
& \left.+768 \gamma^{6} c+21696 \gamma^{5} c-4320 \gamma^{4} c-21600 \gamma^{3} c-7776 \gamma^{2} c\right)(3 \gamma+2)^{-1}(\gamma-2)^{-1}\left(23 \gamma^{2}-54 \gamma-54\right)^{-2}\left(\gamma^{2}-2 \gamma-2\right)^{-2} \\
& \Pi^{L E *}=\frac{1}{36}\left(-1242 \gamma^{6} c+621 \gamma^{6}+825 \gamma^{6} c^{2}-3096 \gamma^{5} c^{2}-3528 \gamma^{5}+5760 \gamma^{5} c+2124 \gamma^{4}+1392 \gamma^{4} c-6352 \gamma^{4} c^{2}+12744 \gamma^{3}\right. \\
& +28072 \gamma^{3} c^{2}-26544 \gamma^{3} c-5436 \gamma^{2}-360 \gamma^{2} c+4148 \gamma^{2} c^{2}-19440 \gamma-37872 \gamma c^{2}+33696 \gamma c-7776+15552 c \\
& \left.-18144 c^{2}\right)(3 \gamma+2)^{-1}(\gamma-2)^{-1}\left(23 \gamma^{2}-54 \gamma-54\right)^{-1}\left(\gamma^{2}-2-2 \gamma\right)^{-1}
\end{aligned}
$$

\section{B. Proofs}

Proof of Lemma A.1. Plugging (2) into $\pi_{2}^{\mathrm{R}}=\left(p_{2 r}-w_{2 r}\right) q_{2 r}$ and solving the first-order condition yield

$$
q_{2 r}^{\mathrm{R} *}=\frac{1-\gamma q_{1 r}-w_{2 r}}{2} .
$$

After substituting (2) and $q_{2 r}^{\mathrm{R} *}$, the problem of the manufacturer is given by $\max _{w_{2 r}} w_{2 r}\left(\left(1-\gamma q_{1 r}-w_{2 r}\right) / 2\right)$; by applying FOCs to it with respect to $w_{2 r}$, we can obtain $w_{2 r}^{\mathrm{R} *}=(1-$ $\left.\gamma q_{1 r}\right) / 2$.

Plugging (2), $q_{2 r}^{\mathrm{R} *}$, and $w_{2 r}^{\mathrm{R} *}$ into $\pi_{q_{1 r}}^{\mathrm{R}}=\pi_{1}^{\mathrm{R}}+\pi_{2}^{\mathrm{R} *}=\left(p_{1 r}-\right.$ $\left.w_{1 r}\right) q_{1 r}+\pi_{2}^{\mathrm{R} *}$ and solving the first-order condition yield

$$
q_{1 r}^{\mathrm{R} *}=\frac{8-8 w_{1 r}+5 \gamma}{16 \gamma+16-5 \gamma^{2}}
$$

Plugging (2), $q_{2 r}^{\mathrm{R} *}, w_{2 r}^{\mathrm{R} *}$, and $q_{1 r}^{\mathrm{R} *}$ into $\Pi_{w_{1 r}}^{\mathrm{R}}=\Pi_{1}^{\mathrm{R}}+\Pi_{2}^{\mathrm{R} *}=$ $w_{1 r} q_{1 r}+\Pi_{2}^{\mathrm{R} *}$ and solving the first-order condition yield

$$
w_{1 r}^{\mathrm{R} *}=\frac{45 \gamma^{3}-56 \gamma^{2}-240 \gamma-128}{32\left(3 \gamma^{2}-8 \gamma-8\right)} .
$$

Substituting $w_{1 r}^{\mathrm{R} *}$ into $q_{2 r}^{\mathrm{R} *}, w_{2 r}^{\mathrm{R} *}, q_{1 r}^{\mathrm{R} *}$, and the profits of all members provides the equilibrium outcomes in Lemma A.1.
Proof of Lemma A.2. Plugging (3) into $\max _{q_{2 m}} \Pi_{2}^{\mathrm{RE}}=w_{2 r} q_{2 r}+$ $p_{2 r} q_{2 m}-c q_{2 m}$ and solving the first-order condition yield

$$
q_{2 m}^{\mathrm{RE} *}=\frac{1-\gamma q_{1 r}-\gamma q_{1 m}-q_{2 r}-c}{2} .
$$

Plugging (3) and $q_{2 m}^{\mathrm{RE} *}$ into $\max _{q_{2 r}} \pi_{2}^{\mathrm{RE}}=p_{2 r} q_{2 r}-w_{2 r} q_{2 r}$ and solving the first-order condition yield

$$
q_{2 r}^{\mathrm{RE} *}=\frac{1+c-\gamma q_{1 r}-\gamma q_{1 m}-w_{2 l}}{2}
$$

Plugging (3), $q_{2 m}^{\mathrm{RE} *}$, and $q_{2 r}^{\mathrm{RE} *}$ into $\max _{w_{2 r}} \Pi_{2}^{\mathrm{RE}}=w_{2 r} q_{2 r}+$ $p_{2 r} q_{2 m}-c q_{2 m}$ and solving the first-order condition yield

$$
w_{2 r}^{\mathrm{RE} *}=\frac{3-c-3 \gamma q_{1 r}-3 \gamma q_{1 m}}{6} .
$$

Plugging (3), $q_{2 m}^{\mathrm{RE} *}, q_{2 r}^{\mathrm{RE} *}$, and $w_{2 r}^{\mathrm{RE} *}$ into $\max _{q_{1 m}} \Pi^{\mathrm{RE}}=$ $w_{1 r} q_{1 r}+p_{1 r} q_{1 m}-c q_{1 m}+\Pi_{2}^{\mathrm{RE} *}$ and solving the first-order condition yield

$$
q_{1 m}^{\mathrm{RE} *}=\frac{2\left(3 \gamma^{2} q_{1 r}-3 \gamma q_{1 r}+2 c \gamma-3 c+3-3 q_{1 r}\right)}{3\left(4 \gamma+4-3 \gamma^{2}\right)} .
$$

Plugging (3), $q_{2 m}^{\mathrm{RE} *}, q_{2 r}^{\mathrm{RE} *}, w_{2 r}^{\mathrm{RE} *}$, and $q_{1 m}^{\mathrm{RE} *}$ into $\max _{q_{1 r}} \pi^{\mathrm{RE}}=$ $p_{1 r} q_{1 r}-w_{1 r} q_{1 r}+\pi_{2}^{\mathrm{RE} *}$ and solving the first-order condition yield

$$
q_{1 m}^{\mathrm{RE} *}=\frac{c \gamma^{3}-24 w_{1 r} \gamma-24 w_{1 r}+24 \gamma+8 c \gamma+12-9 \gamma^{3}+12 c-10 c \gamma^{2}+18 w_{1 r} \gamma^{2}}{6\left(4+8 \gamma-4 \gamma^{3}+\gamma^{4}\right)}
$$

Plugging (3), $q_{2 m}^{\mathrm{RE} *}, q_{2 r}^{\mathrm{RE} *}, w_{2 r}^{\mathrm{RE} *}, q_{1 m}^{\mathrm{RE} *}$, and $q_{1 r}^{\mathrm{RE} *}$ into $\max _{w_{1 r}} \Pi^{\mathrm{RE}}=w_{1 r} q_{1 r}+p_{1 r} q_{1 m}-c q_{1 m}+\Pi_{2}^{\mathrm{RE} *}$ and solving the first-order condition yield

$$
w_{1 r}^{\mathrm{RE} *}=\frac{9 \gamma^{3}+8 c \gamma-c \gamma^{3}-2 c \gamma^{2}-24 \gamma+4 c-12}{6\left(3 \gamma^{2}-4 \gamma-4\right)} .
$$

Substituting $w_{1 r}^{\mathrm{RE} *}$ into $q_{2 m}^{\mathrm{RE} *}, q_{2 r}^{\mathrm{RE} *}, w_{2 r}^{\mathrm{R} *}, q_{1 m}^{\mathrm{RE} *}, q_{1 r}^{\mathrm{RE} *}$, and the profits of all members provides the equilibrium outcomes in Lemma A.2.
Proof of Proposition 1. This proof follows from optimal decisions in Lemma A.2:

(a) We find that when $c<3\left(\gamma^{2}-2 \gamma-2\right)\left(3 \gamma^{2}-2 \gamma-\right.$ 4) $/\left(11 \gamma^{4}+76 \gamma-6 \gamma^{2}-42 \gamma^{3}+40\right)=c_{1}(\gamma)$, the manufacturer opens the e-channel $\left(q_{2 m}^{\mathrm{RE} *}>0\right)$.

(b) We find that when $c>0, q_{2 r}^{\mathrm{RE} *}>0$; otherwise, $q_{2 r}^{\mathrm{RE} *}<0$; that is, when $c<0$, the reseller starts withdrawing from the market. 
Proof of Proposition 2. This proof follows from the equilibrium outcomes in Lemmas A.1 and A.2:

(a) Comparing the equilibrium quantities $q_{2 r}^{\mathrm{RE}}+q_{2 m}^{\mathrm{RE}}\left(q_{1 r}^{\mathrm{RE}}+\right.$ $\left.q_{1 m}^{\mathrm{RE}}\right)$ with $q_{2 r}^{\mathrm{R}}\left(q_{1 r}^{\mathrm{R}}\right)$, we find that $q_{2 r}^{\mathrm{RE}}+q_{2 m}^{\mathrm{RE}}>q_{2 r}^{\mathrm{R}}\left(q_{1 r}^{\mathrm{RE}}+\right.$ $\left.q_{1 m}^{\mathrm{RE}}>q_{1 r}^{\mathrm{R}}\right)$. (b) Comparing $w_{2 r}^{\mathrm{RE}}\left(w_{1 r}^{\mathrm{RE}}\right)$ with $w_{2 r}^{\mathrm{R}}\left(w_{1 r}^{\mathrm{R}}\right)$, we find that $w_{2 r}^{\mathrm{RE}}<w_{2 r}^{\mathrm{R}}$, and there exists a critical value,

$$
c_{2}(\gamma)=\frac{-6 \gamma\left(36+72 \gamma+2 \gamma^{2}-34 \gamma^{3}+9 \gamma^{4}\right)}{1206 \gamma^{5}+1708 \gamma^{2}+3288 \gamma-213 \gamma^{6}-1100 \gamma^{4}-2752 \gamma^{3}+1008}
$$

when $c<c_{2}(\gamma), w_{1 r}^{\mathrm{RE}}>w_{1 r}^{\mathrm{R}}$; otherwise, $w_{1 r}^{\mathrm{RE}}<w_{1 r}^{\mathrm{R}}$.

Proof of Proposition 3. This proof follows from the equilibrium outcomes in Lemmas A.1 and A.2:

(a) Comparing the equilibrium quantities $\Pi^{\mathrm{RE}}$ with $\Pi^{\mathrm{R}}$, we find that $\Pi^{\mathrm{RE}}>\Pi^{\mathrm{R}}$.

(b) Comparing $\pi^{\mathrm{RE}}$ with $\pi^{\mathrm{R}}$, we find that there exists a critical value,

$$
\begin{aligned}
& c_{3}(\gamma)=48 \sqrt{2}\left(\left(\gamma^{4}-4 \gamma^{3}-3 \gamma^{2}+12 \gamma+8\right)\right. \\
& \left.\cdot\left(-864 \gamma^{3}+848 \gamma^{2}+3840 \gamma+2048+99 \gamma^{4}\right)\right)^{1 / 2} \\
& \cdot\left(\gamma^{2}-2-2 \gamma\right)\left(3 \gamma^{2}-8 \gamma-8\right)^{-1}\left(512 \gamma^{4}-2048 \gamma^{3}\right. \\
& \left.-1536 \gamma^{2}+6144 \gamma+4096\right)^{-1} ;
\end{aligned}
$$

when $c>c_{3}(\gamma), \pi^{\mathrm{RE}}>\pi^{\mathrm{R}}$; otherwise, $\pi^{\mathrm{RE}}<\pi^{\mathrm{R}}$.

(c) Comparing $\Pi^{\mathrm{RE}}+\pi^{\mathrm{RE}}$ with $\Pi^{\mathrm{R}}+\pi^{\mathrm{R}}$, we find that there exist two critical values,

$$
\begin{aligned}
& c_{4}(\gamma)=\frac{1}{2}\left(10368 \gamma^{6}-52992 \gamma^{5}+768 \gamma^{4}\right. \\
& +236544 \gamma^{3}-12288 \gamma^{2}-319488 \gamma-147456 \\
& -48\left(29104128 \gamma^{2}-32278912 \gamma^{4}+12686336 \gamma^{3}\right. \\
& -28100032 \gamma^{5}+14435920 \gamma^{6}+2844 \gamma^{11} \\
& -16605 \gamma^{12}+14069696 \gamma^{7}-2348760 \gamma^{9} \\
& -4696964 \gamma^{8}+13008896 \gamma+890880 \gamma^{10} \\
& \left.+1835008)^{1 / 2}\right)\left(\gamma^{2}-2-2 \gamma\right)\left(3 \gamma^{2}-8 \gamma-8\right)^{-1} \\
& .\left(4544 \gamma^{6}-22528 \gamma^{5}-3840 \gamma^{4}+105984 \gamma^{3}\right. \\
& \left.-6400 \gamma^{2}-136192 \gamma-59392\right)^{-1},
\end{aligned}
$$

$$
\begin{aligned}
& c_{5}(\gamma)=\frac{1}{2}\left(10368 \gamma^{6}-52992 \gamma^{5}+768 \gamma^{4}\right. \\
& +236544 \gamma^{3}-12288 \gamma^{2}-319488 \gamma-147456 \\
& +48\left(29104128 \gamma^{2}-32278912 \gamma^{4}+12686336 \gamma^{3}\right. \\
& -28100032 \gamma^{5}+14435920 \gamma^{6}+2844 \gamma^{11} \\
& -16605 \gamma^{12}+14069696 \gamma^{7}-2348760 \gamma^{9} \\
& -4696964 \gamma^{8}+13008896 \gamma+890880 \gamma^{10} \\
& \left.+1835008)^{1 / 2}\right)\left(\gamma^{2}-2-2 \gamma\right)\left(3 \gamma^{2}-8 \gamma-8\right)^{-1} \\
& \cdot\left(4544 \gamma^{6}-22528 \gamma^{5}-3840 \gamma^{4}+105984 \gamma^{3}\right. \\
& \left.-6400 \gamma^{2}-136192 \gamma-59392\right)^{-1} ;
\end{aligned}
$$

when $c_{4}(\gamma)<c<c_{1}(\gamma)$ or $0<c<c_{5}(\gamma)$, the supply chain profit $\pi^{\mathrm{RE}}+\Pi^{\mathrm{RE}}>\pi^{\mathrm{R}}+\Pi^{\mathrm{R}}$; otherwise, the opposite is true.

Proof of Lemma A.3. Plugging (5) into $\pi_{2}^{\mathrm{L}}=\left(l_{2 n}-w_{2 l}\right) q_{2 l}+$ $l_{2 u} q_{1 l}$ and solving the first-order condition yield

$$
q_{2 l}^{\mathrm{L} *}=\frac{1-2 \gamma q_{1 l}-w_{2 l}}{2} .
$$

After substituting (5) and $q_{2 l}^{\mathrm{L} *}$, the problem of the manufacturer is given by $\max _{w_{2 l}} w_{2 l}\left(\left(1-2 \gamma q_{1 l}-w_{2 l}\right) / 2\right)$; by applying FOCs to it with respect to $w_{2 l}$, we can obtain

$$
w_{2 l}^{\mathrm{L} *}=\frac{1-2 \gamma q_{1 l}}{2} .
$$

Plugging (5), $q_{2 l}^{\mathrm{L} *}$, and $w_{2 l}^{\mathrm{L} *}$ into $\pi_{q_{1 l}}^{\mathrm{L}}=\pi_{1}^{\mathrm{L}}+\pi_{2}^{\mathrm{L} *}=\left(l_{1 n}-\right.$ $\left.w_{1 l}\right) q_{1 l}+\pi_{2}^{\mathrm{L} *}$ and solving the first-order condition yield

$$
q_{1 l}^{\mathrm{L} *}=\frac{3 \gamma+4-4 w_{1}}{2\left(4 \gamma+4-\gamma^{2}\right)}
$$


Plugging (5), $q_{2 l}^{\mathrm{L} *}, w_{2 l}^{\mathrm{L} *}$, and $q_{1 l}^{\mathrm{L} *}$ into $\Pi_{w_{1 l}}^{\mathrm{L}}=\Pi_{1}^{\mathrm{L}}+\Pi_{2}^{\mathrm{L} *}=$ $w_{1 l} q_{1 l}+\Pi_{2}^{\mathrm{L} *}$ and solving the first-order condition yield

$$
w_{1 l}^{\mathrm{L} *}=\frac{11 \gamma^{3}-36 \gamma-8 \gamma^{2}-16}{16\left(\gamma^{2}-2-2 \gamma\right)} .
$$

Substituting $w_{1 l}^{\mathrm{L} *}$ into $q_{2 l}^{\mathrm{L} *}, w_{2 l}^{\mathrm{L} *}, q_{1 l}^{\mathrm{L} *}$, and the profits of all members provides the equilibrium outcomes in Lemma A.3.

Proof of Lemma A.4. Plugging (6) into $\max _{q_{2 m}} \Pi_{2}^{\mathrm{LE}}=w_{2 l} q_{2 l}+$ $p_{2 r} q_{2 m}-c q_{2 m}$ and solving the first-order condition yield

$$
q_{2 m}^{\mathrm{LE} *}=\frac{1-\gamma q_{1 l}-\gamma q_{1 m}-q_{2 l}-c}{2} .
$$

Plugging (6) and $q_{2 m}^{\mathrm{LE} *}$ into $\max _{q_{2 r}} \pi_{2}^{\mathrm{LE}}=l_{2 n} q_{2 l}+l_{2 u} q_{1 l}-$ $w_{2 l} q_{2 l}$ and solving the first-order condition yield

$$
q_{2 l}^{\mathrm{LE} *}=\frac{1+c-\gamma q_{1 l}-\gamma q_{1 m}-w_{2 l}}{2} .
$$

Plugging (6), $q_{2 m}^{\mathrm{LE} *}$, and $q_{2 l}^{\mathrm{LE} *}$ into $\max _{w_{2 l}} \Pi_{2}^{\mathrm{LE}}=w_{2 l} q_{2 l}+$ $p_{2 r} q_{2 m}-c q_{2 m}$ and solving the first-order condition yield

$$
w_{2 l}^{\mathrm{LE} *}=\frac{3-c-4 \gamma q_{1 l}-3 \gamma q_{1 m}}{6} .
$$

Plugging (6), $q_{2 m}^{\mathrm{LE} *}, q_{2 l}^{\mathrm{LE} *}$, and $w_{2 l}^{\mathrm{LE} *}$ into $\max _{q_{1 m}} \Pi^{\mathrm{LE}}=$ $w_{1 l} q_{1 l}+p_{1 r} q_{1 m}-c q_{1 m}+\Pi_{2}^{\mathrm{LE} *}$ and solving the first-order condition yield

$$
q_{1 m}^{\mathrm{LE} *}=\frac{7 \gamma^{2} q_{1 l}+4 \gamma c-6 c-6 q_{1 l}+6-6 \gamma q_{1 l}}{3\left(4 \gamma+4-3 \gamma^{2}\right)} .
$$

Plugging (6), $q_{2 m}^{\mathrm{LE} *}, q_{2 l}^{\mathrm{LE} *}, w_{2 l}^{\mathrm{LE} *}$, and $q_{1 m}^{\mathrm{LE} *}$ into $\max _{q_{1 l}} \pi^{\mathrm{LE}}=$ $l_{1 n} q_{1 l}-w_{1 l} q_{1 l}+\pi_{2}^{\mathrm{LE} *}$ and solving the first-order condition yield

$$
q_{1 l}^{\mathrm{LE} *}=\frac{36-3 \gamma^{3} c-72 w_{1 l} \gamma+54 w_{1 l} \gamma^{2}-72 w_{1 l}+32 \gamma c-27 \gamma^{3}+36 c+72 \gamma-22 \gamma^{2} c}{2\left(9 \gamma^{4}+36+2 \gamma^{2}+72 \gamma-34 \gamma^{3}\right)} .
$$

Plugging (6), $q_{2 m}^{\mathrm{LE} *}, q_{2 l}^{\mathrm{LE} *}, w_{2 l}^{\mathrm{LE} *}, q_{1 m}^{\mathrm{LE} *}$, and $q_{1 l}^{\mathrm{LE} *}$ into $\max _{w_{1 l}} \Pi^{\mathrm{LE}}=w_{1 l} q_{1 l}+p_{1 r} q_{1 m}-c q_{1 m}+\Pi_{2}^{\mathrm{LE} *}$ and solving the first-order condition yield

$$
\begin{gathered}
w_{1 l}^{\mathrm{LE} *}=\frac{1}{18}\left(357 c \gamma^{7}+621 \gamma^{7}-2592 \gamma^{6}-2250 c \gamma^{6}\right. \\
-1848 \gamma^{5}+3328 \gamma^{5} c+12228 \gamma^{4}+2684 c \gamma^{4} \\
+6804 \gamma^{3}-6044 \gamma^{3} c-1944 \gamma^{2} c-15408 \gamma^{2} \\
-15552 \gamma+3168 \gamma c+1296 c-3888)\left(69 \gamma^{6}\right.
\end{gathered}
$$

$$
\begin{aligned}
& -392 \gamma^{5}+332 \gamma^{4}+1016 \gamma^{3}-572 \gamma^{2}-1296 \gamma \\
& -432)^{-1} .
\end{aligned}
$$

Substituting $w_{1 l}^{\mathrm{LE} *}$ into $q_{2 m}^{\mathrm{LE} *}, q_{2 l}^{\mathrm{LE} *}, w_{2 l}^{\mathrm{LE} *}, q_{1 m}^{\mathrm{LE} *}, q_{1 l}^{\mathrm{LE} *}$, and the profits of all members provides the equilibrium outcomes in Lemma A.4.

Proof of Proposition 4. This proof follows from optimal decisions in Lemma A.4:

(a) We find that when

$$
c<\frac{3\left(69 \gamma^{6}+136 \gamma^{4}-344 \gamma^{5}+1036 \gamma^{3}-140 \gamma^{2}-1080 \gamma-432\right)}{237 \gamma^{6}-1378 \gamma^{5}+1092 \gamma^{4}+4232 \gamma^{3}-2252 \gamma^{2}-5976 \gamma-2160}=c_{6}(\gamma),
$$

the manufacturer opens the e-channel $\left(q_{2 m}^{\mathrm{LE} *}>0\right)$.

(b) We find that there exists a critical value,

$c_{7}(\gamma)=\frac{3 \gamma^{3}}{15 \gamma^{4}-62 \gamma^{3}-20 \gamma^{2}+180 \gamma+108} ;$

when $c>c_{7}(\gamma), q_{2 l}^{\mathrm{LE} *}>0$; otherwise, $q_{2 l}^{\mathrm{LE} *} \leq 0$; that is, when $c<c_{7}(\gamma)$, the leaser starts withdrawing from the market in Period 2.
Proof of Proposition 5. This proof follows from the equilibrium outcomes in Lemmas A.3 and A.4:

(a) Comparing the equilibrium quantities $q_{2 l}^{\mathrm{LE}}+q_{2 m}^{\mathrm{LE}}\left(q_{1 l}^{\mathrm{LE}}+\right.$ $\left.q_{1 m}^{\mathrm{LE}}\right)$ with $q_{2 l}^{\mathrm{L}}\left(q_{1 l}^{\mathrm{L}}\right)$, we find that $q_{2 l}^{\mathrm{LE}}+q_{2 m}^{\mathrm{LE}}>q_{2 l}^{\mathrm{L}}\left(q_{1 l}^{\mathrm{LE}}+\right.$ $\left.q_{1 m}^{\mathrm{LE}}>q_{1 l}^{\mathrm{L}}\right)$.

(b) Comparing $w_{2 l}^{\mathrm{LE}}\left(w_{1 l}^{\mathrm{LE}}\right)$ with $w_{2 l}^{\mathrm{L}}\left(w_{1 l}^{\mathrm{L}}\right)$, we find that $w_{1 l}^{\mathrm{LE}}<w_{1 l}^{\mathrm{L}}$; and there exists a critical value, 


$$
c_{8}(\gamma)=\frac{3 \gamma\left(2318 \gamma^{4}+6680 \gamma^{3}-5088 \gamma^{2}-8928 \gamma-2592+621 \gamma^{6}-3126 \gamma^{5}\right)}{8\left(3328 \gamma^{5}-6044 \gamma^{3}-1944 \gamma^{2}-2250 \gamma^{6}+357 \gamma^{7}+3168 \gamma+1296+2684 \gamma^{4}\right)}
$$

when $c<c_{8}(\gamma), w_{2 l}^{\mathrm{LE}}>w_{2 l}^{\mathrm{L}}$; otherwise, $w_{2 l}^{\mathrm{LE}}<w_{2 l}^{\mathrm{L}}$.

Proof of Proposition 6. This proof follows from the equilibrium outcomes in Lemmas A.3 and A.4:

(a) Comparing the equilibrium quantities $\Pi^{\mathrm{LE}}$ with $\Pi^{\mathrm{L}}$, we find that $\Pi^{\mathrm{LE}}>\Pi^{\mathrm{L}}$.

(b) Comparing $\pi^{\mathrm{LE}}$ with $\pi^{\mathrm{L}}$, we find that there exists a critical value,

$c_{9}(\gamma)=\frac{1}{2}\left(3981312 \gamma^{2}-11108352 \gamma^{5}-393216 \gamma^{6}\right.$

$+4792320 \gamma^{7}-1886208 \gamma^{8}+221184 \gamma^{9}$

$+2211840 \gamma^{4}+11059200 \gamma^{3}$

$-96\left(8819462062080 \gamma^{2}+2116748630016 \gamma^{4}\right.$

$+13392227819520 \gamma^{3}-18703415808000 \gamma^{5}$

$-15671382838272 \gamma^{6}+278628139008$

$+2285906678528 \gamma^{11}+2498220801696 \gamma^{12}$

$-15037686912 \gamma^{17}+48133710 \gamma^{20}$

$-902043072 \gamma^{19}+6283751376 \gamma^{18}$

$-1090461701888 \gamma^{13}-37302592776 \gamma^{16}$

$+276600397856 \gamma^{15}-316861457856 \gamma^{14}$

$+10684931867136 \gamma^{7}-4480236638208 \gamma^{9}$

$+15181519996032 \gamma^{8}+2515392921600 \gamma$

$\left.\left.-8010597677824 \gamma^{10}\right)^{1 / 2}\right)\left(243105792 \gamma^{4}\right.$

$-95657984 \gamma^{6}-66994176 \gamma^{5}+130793472 \gamma^{3}$

$-216391680 \gamma^{2}-204374016 \gamma-47775744$

$+39342080 \gamma^{7}+4894720 \gamma^{8}-4233216 \gamma^{9}$

$\left.+517632 \gamma^{10}\right)^{-1}$;

when $c>c_{9}(\gamma), \pi^{\mathrm{LE}}>\pi^{\mathrm{L}}$; otherwise, $\pi^{\mathrm{LE}}<\pi^{\mathrm{L}}$.

(c) Comparing $\Pi^{\mathrm{LE}}+\pi^{\mathrm{LE}}$ with $\Pi^{\mathrm{L}}+\pi^{\mathrm{L}}$, we find that there exist two critical values,

$c_{10}(\gamma)=\frac{1}{2}\left(-108478464 \gamma^{5}+552480768 \gamma^{4}\right.$

$+281788416 \gamma^{3}-467306496 \gamma^{2}+66994176 \gamma^{7}$

$$
\begin{aligned}
& +33564672 \gamma^{8}-16206336 \gamma^{9}+1828224 \gamma^{10} \\
& -107495424-447897600 \gamma-241499136 \gamma^{6} \\
& -48\left(975198486528+39312097763328 \gamma^{2}\right. \\
& +21201744743424 \gamma^{4}+69051360743424 \gamma^{3} \\
& -103862582470656 \gamma^{5}-117015589324800 \gamma^{6} \\
& +4401973467904 \gamma^{11}+26731202768272 \gamma^{12} \\
& +163151540580 \gamma^{16}-333695359704 \gamma^{17} \\
& +548767143 \gamma^{20}-11408569848 \gamma^{19} \\
& +92958565536 \gamma^{18}-5398938263616 \gamma^{13} \\
& +2454413485232 \gamma^{15}-5569297462912 \gamma^{14} \\
& + \\
& +48833163728640 \gamma^{7}-8626694923648 \gamma^{9} \\
& +121365459983552 \gamma^{8}+9918387781632 \gamma \\
& + \\
& +
\end{aligned}
$$




$$
\begin{aligned}
& +92958565536 \gamma^{18}-5398938263616 \gamma^{13} \\
& +2454413485232 \gamma^{15}-5569297462912 \gamma^{14} \\
& +48833163728640 \gamma^{7}-8626694923648 \gamma^{9} \\
& +121365459983552 \gamma^{8}+9918387781632 \gamma \\
& \left.\left.-70834170203136 \gamma^{10}\right)^{1 / 2}\right)\left(805064704 \gamma^{4}\right. \\
& -309561856 \gamma^{6}-244125696 \gamma^{5}+478900224 \gamma^{3} \\
& -720552960 \gamma^{2}-716967936 \gamma-173187072 \\
& +131136512 \gamma^{7}+15781376 \gamma^{8}-14070528 \gamma^{9} \\
& \left.+1732032 \gamma^{10}\right)^{-1} ;
\end{aligned}
$$

when $c_{10}(\gamma)<c<c_{6}(\gamma)$ or $0<c<c_{11}(\gamma)$, the supply chain profit $\pi^{\mathrm{LE}}+\Pi^{\mathrm{LE}}>\pi^{\mathrm{L}}+\Pi^{\mathrm{L}}$; otherwise, the opposite is true.

Proof of Proposition 7. This proof follows from optimal decisions in Lemmas A.2 and A.4.

Comparing $\pi^{\mathrm{RE}}\left(\Pi^{\mathrm{RE}}\right)$ with $\pi^{\mathrm{LE}}\left(\Pi^{\mathrm{LE}}\right)$, we find that there exists a critical value,

$$
\begin{aligned}
& c_{12}(\gamma)=\frac{\gamma}{2}\left(768 \gamma^{4}-9360 \gamma^{5}-432 \gamma^{7}+3684 \gamma^{6}\right. \\
& -21600 \gamma-7776+21696 \gamma^{3}-4320 \gamma^{2} \\
& -6\left(1679616+19657728 \gamma^{2}-22624560 \gamma^{4}\right. \\
& +5909760 \gamma^{3}-15102144 \gamma^{5}+13818536 \gamma^{6} \\
& +8279448 \gamma^{7}-1032280 \gamma^{9}-6610920 \gamma^{8} \\
& +1734738 \gamma^{10}+42849 \gamma^{12}-477342 \gamma^{11} \\
& \left.+10077696 \gamma)^{1 / 2}\right)\left(83788 \gamma^{3}+33067 \gamma^{7}\right. \\
& -39852 \gamma^{6}-61760 \gamma^{5}+116824 \gamma^{4}+576 \gamma^{9} \\
& \left.-7648 \gamma^{8}-93888 \gamma^{2}-92736 \gamma-20736\right)^{-1}
\end{aligned}
$$

when $c<c_{12}(\gamma)$, (a) $\pi^{\mathrm{LE}}>\pi^{\mathrm{RE}}$ and (b) $\Pi^{\mathrm{LE}}>\Pi^{\mathrm{RE}}$; otherwise, $\pi^{\mathrm{LE}}<\pi^{\mathrm{RE}}$ and $\Pi^{\mathrm{LE}}<\Pi^{\mathrm{RE}}$.

Proof of Proposition 8. This proof follows from optimal decisions in Lemmas A.1, A.2, A.3, and A.4:

(a) Comparing $\Delta \pi^{\mathrm{R}}=\pi^{\mathrm{RE}}-\pi^{\mathrm{R}}$ with $\Delta \pi^{\mathrm{L}}=\pi^{\mathrm{LE}}-\pi^{\mathrm{L}}$, we find that there exists a critical value,

$$
\begin{gathered}
c_{13}(\gamma)=\frac{1}{2}\left(73728 r^{9}-978944 r^{8}+4232576 r^{7}\right. \\
-5101056 r^{6}-7905280 r^{5}+14953472 r^{4}
\end{gathered}
$$

$$
\begin{aligned}
& +10724864 r^{3}-12017664 r^{2}-11870208 r \\
& -2654208)\left(-165888 r^{10}+1857024 r^{9}\right. \\
& -6924288 r^{8}+6107136 r^{7}+17129472 r^{6} \\
& -24662016 r^{5}-26087424 r^{4}+23556096 r^{3} \\
& +30081024 r^{2}+7962624 r+48(123834728448 \\
& +1180729737216 r-2411259052032 r^{4} \\
& +6041802203136 r^{3}+15118687095424 r^{7} \\
& -11165865072768 r^{6}-16775099375616 r^{5} \\
& -7433595964736 r^{9}+18618855245536 r^{8} \\
& -14231489629152 r^{10}-1813386025720 r^{14} \\
& +1740206450432 r^{13}+3204102325312 r^{11} \\
& +165219478380 r^{17}+765951670936 r^{15} \\
& +190740007966 r^{16}+22654457950 r^{18} \\
& -16454016 r^{22}-2708248626 r^{20} \\
& \left.\left.-16719788 r^{19}+350581824 r^{21}\right)^{1 / 2}\right)\left(3 r^{2}\right. \\
& -10
\end{aligned}
$$

when $c<c_{13}(\gamma), \Delta \pi^{\mathrm{R}}<\Delta \pi^{\mathrm{L}}<0$; when $c_{13}(\gamma)<$ $c<c_{10}(\gamma), 0>\Delta \pi^{\mathrm{R}}>\Delta \pi^{\mathrm{L}}$; when $c>c_{10}(\gamma), \Delta \pi^{\mathrm{R}}>$ $\Delta \pi^{\mathrm{L}}>0$.

(b) Comparing $\Delta \Pi^{\mathrm{R}}=\Pi^{\mathrm{RE}}-\Pi^{\mathrm{R}}$ with $\Delta \Pi^{\mathrm{L}}=\Pi^{\mathrm{LE}}-\Pi^{\mathrm{L}}$, we find that there exists a critical value,

$$
\begin{aligned}
& c_{14}(\gamma)=\frac{1}{2}\left(1568768 r^{4}-87040 r^{8}+398496 r^{7}\right. \\
& -512064 r^{6}-779328 r^{5}+6144 r^{9}+1116160 r^{3} \\
& \left.-1318912 r^{2}-1306624 r-294912\right)\left(294912 r^{4}\right. \\
& +43392 r^{7}-4608 r^{8}-121344 r^{6}+19968 r^{5} \\
& -110592 r-69120 r^{3}-307200 r^{2} \\
& -24\left(-79488 r^{18}+1392192 r^{17}+127401984\right. \\
& +1050181632 r-2424792064 r^{4} \\
& +3340107776 r^{3}+3166507008 r^{2} \\
& +6639512256 r^{7}-1081918016 r^{6} \\
& -7365509120 r^{5}-3872791552 r^{9}
\end{aligned}
$$




$$
\begin{aligned}
& +1951836624 r^{8}-736945864 r^{10} \\
& +102254842 r^{14}-326200624 r^{13}-77091060 r^{12} \\
& +1545973096 r^{11}+5900110 r^{15} \\
& \left.\left.-7909782 r^{16}\right)^{1 / 2}\right)
\end{aligned}
$$

when $c<c_{14}(\gamma), \Delta \Pi^{\mathrm{L}}>\Delta \Pi^{\mathrm{R}}>0$; otherwise, $\Delta \Pi^{\mathrm{R}}>$ $\Delta \Pi^{\mathrm{L}}>0$.

\section{Competing Interests}

The authors declare that they have no competing interests.

\section{Acknowledgments}

The authors thank the Humanities and Social Sciences Foundation for Young Scholars of China's Ministry of Education (15YJC630154), National Natural Science Foundation of China (71531003, 71272127, and 71272130), and the Fundamental Research Funds for the Central Universities (ZYGX2015KYQD080) for supporting this research.

\section{References}

[1] L. P. Bucklin, "Retail strategy and the classification of consumer goods," Journal of Marketing, vol. 27, no. 1, pp. 50-55, 1963.

[2] J. F. Cady, "Reasonable rules and rules of reason: vertical restrictions on distributors," Journal of Marketing, vol. 46, no. 3, pp. 27-37, 1982.

[3] G. L. Frazier and R. C. Rody, "The use of influence strategies in interfirm relationships in industrial product channels," Journal of Marketing, vol. 55, no. 1, pp. 52-69, 1991.

[4] S. Dutta, M. Bergen, J. B. Heide, and G. John, "Understanding dual distribution: the case of reps and house accounts," Journal of Law, Economics, \& Organization, vol. 11, no. 1, pp. 189-204, 1995.

[5] G. L. Frazier, "Organizing and managing channels of distribution," Journal of the Academy of Marketing Science, vol. 27, no. 2, pp. 226-240, 1999.

[6] F. M. Scherer, "The economics of vertical restraints," Antitrust Law Journal, vol. 52, pp. 687-707, 1983.

[7] T. R. Sass and D. S. Saurman, "Mandated exclusive territories and economic efficiency: an empirical analysis of the maltbeverage industry," The Journal of Law and Economics, vol. 36, no. 1, part 1, pp. 153-177, 1993.

[8] R. T. Moriarty and U. Moran, "Managing hybrid marketing systems," Harvard Business Review, vol. 68, no. 6, pp. 146-155, 1990.

[9] Apple, Welcome to Apple Store, 2013, http://store.apple.com/us/ browse/home/specialdeals.

[10] Hewlett-Packard, "HP Store UK," 2013, http://h20386.www2 .hp.com/UKStore.

[11] Lenovo, "Lenovo Online Store," 2013, http://www.lenovo.com/ uk/en/.
[12] K. L. Webb and C. J. Lambe, "Internal multi-channel conflict: an exploratory investigation and conceptual framework," Industrial Marketing Management, vol. 36, no. 1, pp. 29-43, 2007.

[13] H. Wilson and E. Daniel, "The multi-channel challenge: a dynamic capability approach," Industrial Marketing Management, vol. 36, no. 1, pp. 10-20, 2007.

[14] Microscope, "Resellers clash with HP over direct sales," 2009, http://www.microscope.co.uk/news/2240152990/Resellers-clash-with-HP-over-direct-sales.

[15] A. Sharma and A. Mehrotra, "Choosing an optimal channel mix in multichannel environments," Industrial Marketing Management, vol. 36, no. 1, pp. 21-28, 2007.

[16] A. Arya, B. Mittendorf, and D. E. M. Sappington, "The bright side of supplier encroachment," Marketing Science, vol. 26, no. 5, pp. 651-659, 2007.

[17] Y. Xiong, W. Yan, K. Fernandes, Z.-K. Xiong, and N. Guo, "Bricks vs. clicks': the impact of manufacturer encroachment with a dealer leasing and selling of durable goods," European Journal of Operational Research, vol. 217, no. 1, pp. 75-83, 2012.

[18] J. Bulow, "An economic theory of planned obsolescence," The Quarterly Journal of Economics, vol. 101, no. 4, pp. 729-749, 1986.

[19] P. S. Desai and D. Purohit, "Competition in durable goods markets: the strategic consequences of leasing and selling," Marketing Science, vol. 18, no. 1, pp. 42-58, 1999.

[20] S. Huang, Y. Yang, and K. Anderson, "A theory of finitely durable goods monopoly with used-goods market and transaction costs," Management Science, vol. 47, no. 11, pp. 1515-1532, 2001.

[21] V. V. Agrawal, M. Ferguson, L. B. Toktay, and V. M. Thomas, "Is leasing greener than selling?" Management Science, vol. 58, no. 3, pp. 523-533, 2012.

[22] J. B. Heide, "Plural governance in industrial purchasing," Journal of Marketing, vol. 67, no. 4, pp. 18-29, 2003.

[23] R. Srinivasan, "Dual distribution and intangible firm value: franchising in restaurant chains," Journal of Marketing, vol. 70, no. 3, pp. 120-135, 2006.

[24] G. Gigerenzer and W. Gaissmaier, "Heuristic decision making," Annual Review of Psychology, vol. 62, pp. 451-482, 2011.

[25] N. L. Stokey, "Rational expectations and durable goods pricing," The Bell Journal of Economics, vol. 12, no. 1, pp. 112-128, 1981.

[26] R. H. Coase, "Durability and monopoly," The Journal of Law and Economics, vol. 15, no. 1, pp. 143-149, 1972.

[27] J. I. Bulow, "Durable-goods monopolists," The Journal of Political Economy, vol. 90, no. 2, pp. 314-332, 1982.

[28] P. Desai and D. Purohit, "Leasing and selling: optimal marketing strategies for a durable goods firm," Management Science, vol. 44, no. 11, pp. S19-S34, 1998.

[29] S. Poddar, "Strategic choice in durable goods market when firms move simultaneously," Research in Economics, vol. 58, no. 2, pp. 175-186, 2004.

[30] S. R. Bhaskaran and S. M. Gilbert, "Implications of channel structure for leasing or selling durable goods," Marketing Science, vol. 28, no. 5, pp. 918-934, 2009.

[31] M. Waldman, "Durable goods theory for real world markets," The Journal of Economic Perspectives, vol. 17, no. 1, pp. 131-154, 2003.

[32] A. Andrikopoulos and R. N. Markellos, "Dynamic interaction between markets for leasing \& selling automobiles," Journal of Banking and Finance, vol. 50, pp. 260-270, 2015. 
[33] S. R. Bhaskaran and S. M. Gilbert, "Implications of channel structure and operational mode upon a manufacturer's durability choice," Production and Operations Management, vol. 24, no. 7, pp. 1071-1085, 2015.

[34] E. Anderson and B. Weitz, "The use of pledges to build and sustain commitment in distribution channels," Journal of Marketing Research, vol. 29, no. 1, pp. 18-34, 1992.

[35] S. Balasubramanian, "Mail versus mall: a strategic analysis of competition between direct marketers and conventional retailers," Marketing Science, vol. 17, no. 3, pp. 181-195, 1998.

[36] Y. Lee, Z. Lee, and K. R. T. Larsen, "Coping with Internet channel conflict," Communications of the ACM, vol. 46, no. 7, pp. 137-142, 2003.

[37] K. Cattani, W. Gilland, H. S. Heese, and J. Swaminathan, "Boiling frogs: pricing strategies for a manufacturer adding a direct channel that competes with the traditional channel," Production and Operations Management, vol. 15, no. 1, pp. 4056, 2006.

[38] B. Dan, G. Xu, and C. Liu, "Pricing policies in a dual-channel supply chain with retail services," International Journal of Production Economics, vol. 139, no. 1, pp. 312-320, 2012.

[39] B. Betzabé and G. Aydın, "Pricing and assortment decisions for a manufacturer selling through dual channels," European Journal of Operational Research, vol. 242, no. 3, pp. 901-909, 2015.

[40] S. Panda, N. M. Modak, S. S. Sana, and M. Basu, "Pricing and replenishment policies in dual-channel supply chain under continuous unit cost decrease," Applied Mathematics and Computation, vol. 256, pp. 913-929, 2015.

[41] A. J. Fein and E. Anderson, "Patterns of credible commitments: territory and brand selectivity in industrial distribution channels," Journal of Marketing, vol. 61, no. 2, pp. 19-34, 1997.

[42] S. Dutta, J. B. Heide, and M. Bergen, "Vertical territorial restrictions and public policy: theories and industry evidence," Journal of Marketing, vol. 63, no. 4, pp. 121-134, 1999.

[43] W.-Y. K. Chiang, D. Chhajed, and J. D. Hess, "Direct-marketing, indirect profits: a strategic analysis of dual-channel supplychain design," Management Science, vol. 49, no. 1, pp. 1-20, 2003.

[44] A. Dumrongsiri, M. Fan, A. Jain, and K. Moinzadeh, "A supply chain model with direct and retail channels," European Journal of Operational Research, vol. 187, no. 3, pp. 691-718, 2008.

[45] G. S. Cai, "Channel selection and coordination in dual-channel supply chains," Journal of Retailing, vol. 86, no. 1, pp. 22-36, 2010.

[46] P. Rey and J. Stiglitz, "Vertical restraints and producers' competition," European Economic Review, vol. 32, no. 2-3, pp. 561-568, 1988.

[47] P. Rey and J. Stiglitz, "The role of exclusive territories in producers' competition," The RAND Journal of Economics, vol. 26, no. 3, pp. 431-451, 1995.

[48] L. M. Ausubel and R. J. Deneckere, "Reputation in bargaining and durable goods monopoly," Econometrica, vol. 57, no. 3, pp. 511-531, 1989.

[49] N. H. M. Von der Fehr and K. U. Kühn, "Coase versus pacman: who eats whom in the durable-goods monopoly?" Journal of Political Economy, vol. 103, no. 4, pp. 785-812, 1995.

[50] A. R. Biehl, "Durable-goods monopoly with stochastic values," RAND Journal of Economics, vol. 32, no. 3, pp. 565-577, 2001

[51] S. Bucovetsky and J. Chilton, "Concurrent renting and selling in a durable-goods monopoly under threat of entry," The RAND Journal of Economics, vol. 17, no. 2, pp. 261-275, 1986.
[52] A. A. Tsay and N. Agrawal, "Channel conflict and coordination in the E-commerce age," Production and Operations Management, vol. 13, no. 1, pp. 93-110, 2004.

[53] J. Chen, H. Zhang, and Y. Sun, "Implementing coordination contracts in a manufacturer Stackelberg dual-channel supply chain," Omega, vol. 40, no. 5, pp. 571-583, 2012.

[54] Z. Ning, T.-M. Choi, C. Xie, L. Xie, and J. Dai, "Impact of e-marketplace on supply chain under the markdown policy," Supply Chain Management, vol. 16, no. 6, pp. 409-418, 2011. 


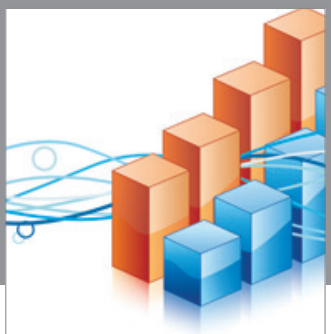

Advances in

Operations Research

vatem alat4

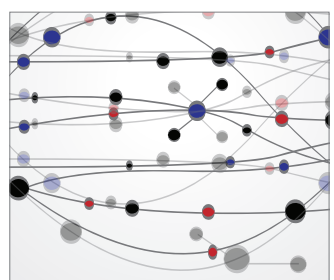

\section{The Scientific} World Journal
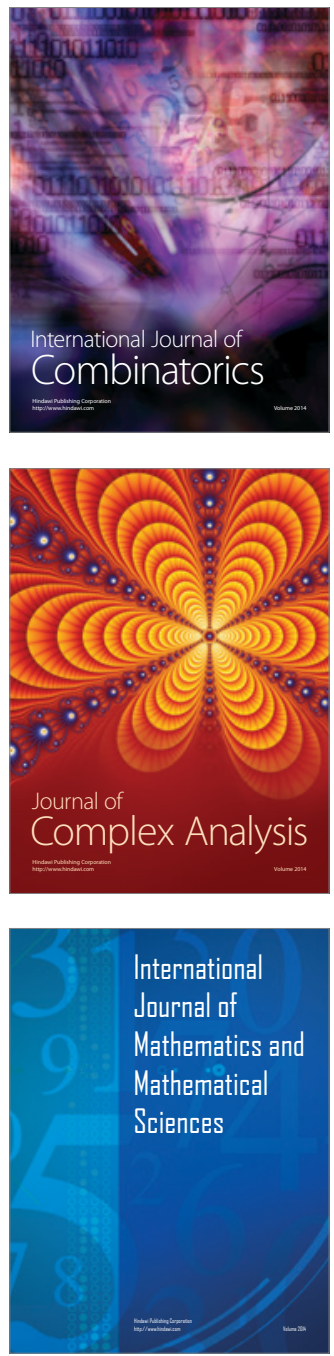
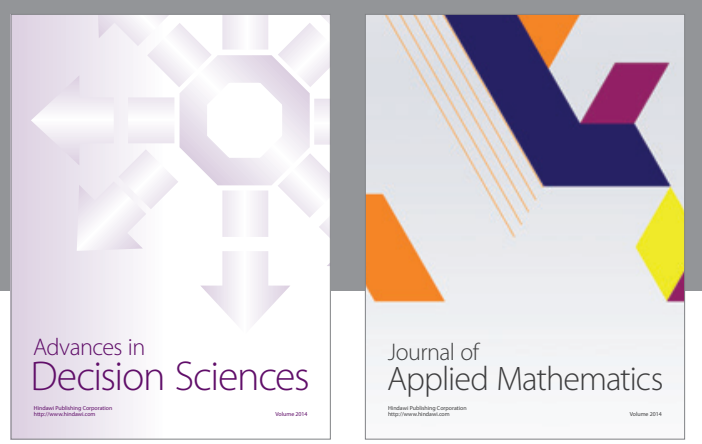

Algebra

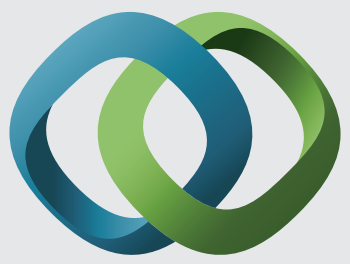

\section{Hindawi}

Submit your manuscripts at

http://www.hindawi.com
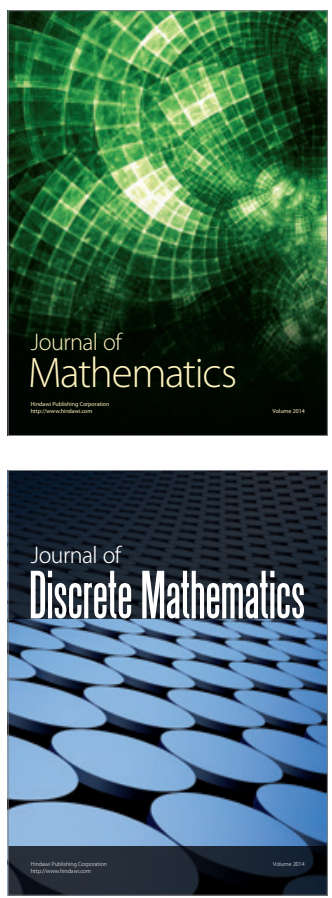

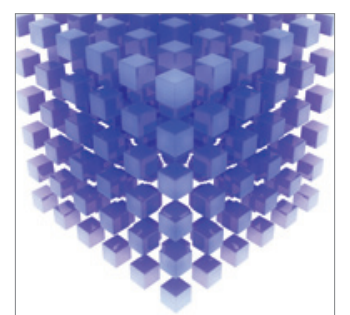

Mathematical Problems in Engineering
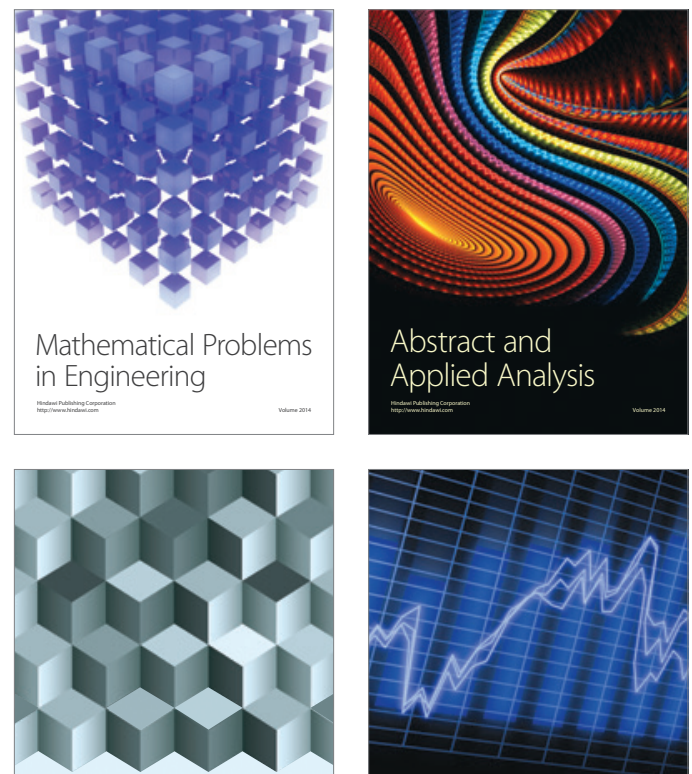

Journal of

Function Spaces

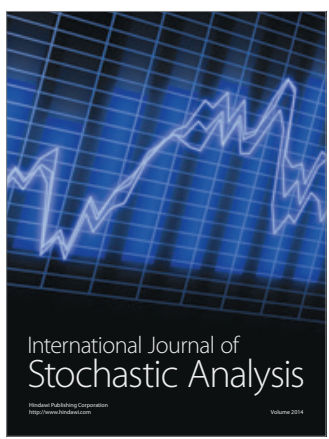

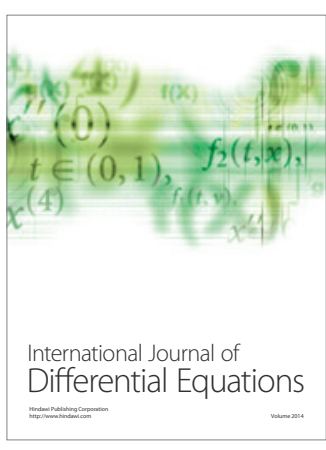
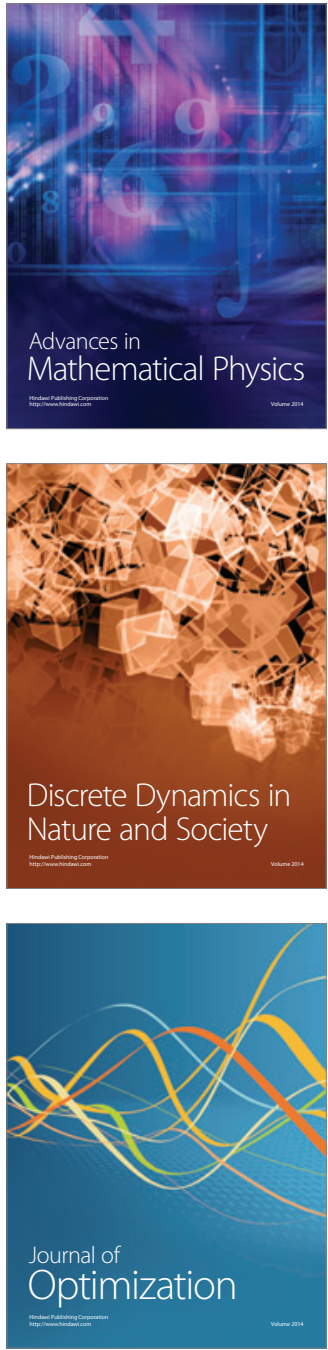